UNIVERSIDADE DE BRASÍLIA

FACULDADE DE AGRONOMIA E MEDICINA VETERINÁRIA

PROGRAMA DE PÓS-GRADUAÇÃO EM AGRONOMIA

DEGRADAÇÃO DE MANCOZEBE POR OZONIZAÇÃO E ADSORÇÃO EM VERMICULITA

KARLOS EDWARD RODRIGUES DE SANTANA

DISSERTAÇÃO DE MESTRADO EM AGRONOMIA

BRASÍLIA/DF

FEVEREIRO/2016 


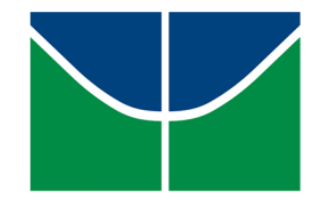

UNIVERSIDADE DE BRASÍLIA

FACULDADE DE AGRONOMIA E MEDICINA VETERINÁRIA

PROGRAMA DE PÓS-GRADUAÇÃO EM AGRONOMIA

DEGRADAÇÃO DE MANCOZEBE POR OZONIZAÇÃO E ADSORÇÃO EM VERMICULITA

KARLOS EDWARD RODRIGUES DE SANTANA

ORIENTADORA: Dra. ANA MARIA RESENDE JUNQUEIRA COORIENTADORA: Dra. MARIA HOSANA CONCEIÇÃO

DISSERTAÇÃO DE MESTRADO EM AGRONOMIA

PUBLICAÇÃO: 111/2016

BRASÍLIA/DF

FEVEREIRO/2016 


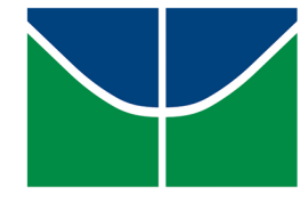

UNIVERSIDADE DE BRASÍLIA

FACULDADE DE AGRONOMIA E MEDICINA VETERINÁRIA PROGRAMA DE PÓS-GRADUAÇÃO EM AGRONOMIA

\section{DEGRADAÇÃO DE MANCOZEBE POR OZONIZAÇÃO E ADSORÇÃO EM VERMICULITA}

KARLOS EDWARD RODRIGUES DE SANTANA

DISSERTAÇÃO DE MESTRAdO SUBMETIDA AO PROGRAMA DE PÓS-GRADUAÇÃO EM AGRONOMIA, COMO PARTE DOS REQUISITOS NECESSÁRIOS À OBTENÇÃO DO GRAU DE MESTRE EM AGRONOMIA.

APROVADO POR:

ANA MARIA RESENDE JUNQUEIRA, PhD (UnB -FAV)

(ORIENTADORA)

ERNANDES RODRIGUES DE ALENCAR, Dr. (UnB -FAV)

(EXAMINADOR INTERNO)

LUIZ ANTONIO BORGO, Dr. (UnB -FAV)

(EXAMINADOR EXTERNO)

BRASÍLIA/DF, 26 de fevereiro de 2016. 


\section{FICHA CATALOGRÁFICA}

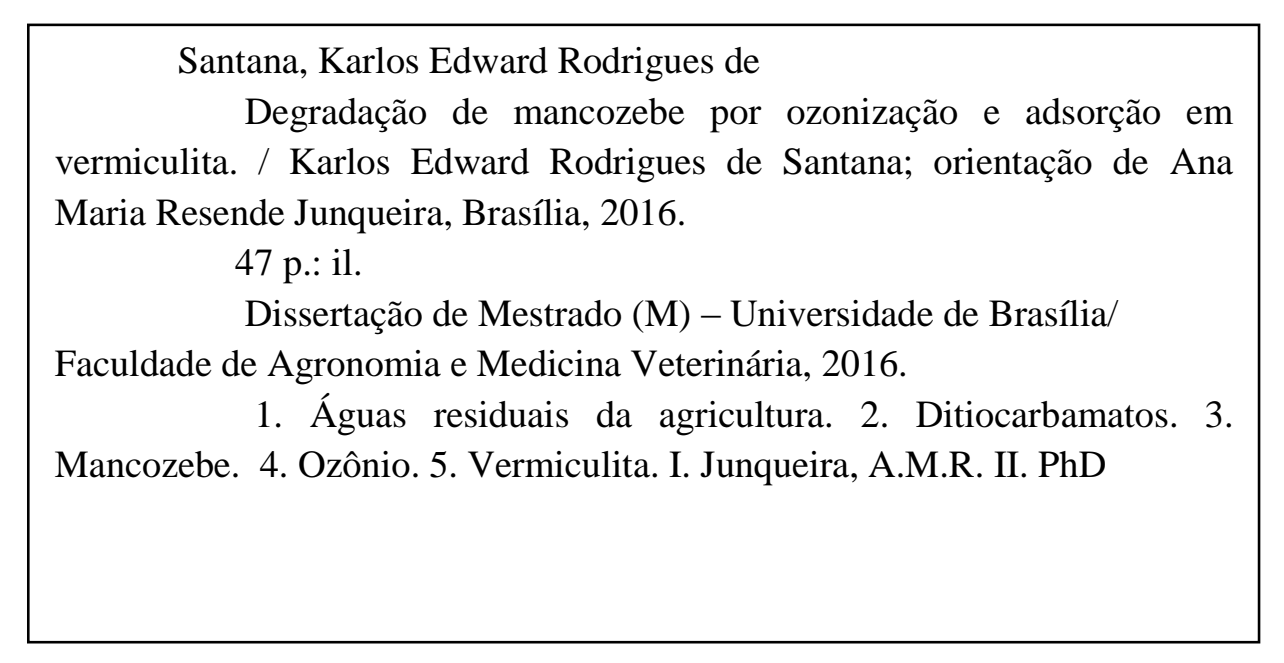

\section{REFERÊNCIA BIBLIOGRÁFICA E CATALOGAÇÃO}

SANTANA, K.E.R. Degradação de mancozebe por ozonização e adsorção em vermiculita. Brasília: Faculdade de Agronomia e Medicina Veterinária, Universidade de Brasília, 2016, 47 p. Dissertação de Mestrado.

\section{CESSÃO DE DIREITOS}

NOME DO AUTOR: Karlos Edward Rodrigues de Santana.

TÍTULO DA DISSERTAÇÃO: Degradação de mancozebe por ozonização e adsorção em vermiculita. GRAU: Mestre ANO: 2016

É concedida à Universidade de Brasília permissão para reproduzir cópias desta dissertação de mestrado para única e exclusivamente propósitos acadêmicos e científicos. $\mathrm{O}$ autor reserva para si os outros direitos autorais, de publicação. Nenhuma parte desta dissertação de mestrado pode ser reproduzida sem a autorização por escrito do autor. Citações são estimuladas, desde que citada a fonte.

Karlos Edward Rodrigues de Santana

CPF: 003.791.911-30

SGCV Lotes 27/30 Bloco H Apto. 805. Guará. 71215-770 Brasília/DF - Brasil

(61) 9964 - 3004 / 3546 - 3004 Email: kers_kadu@ hotmail.com 
A Deus, responsável por tudo em minha vida, que me fortalece, me guarda, me orienta e me conforta.

Aos meus pais, Rute Rodrigues dos Santos e José Carlos de Santana, por serem os meus exemplos, a minha base, os maiores incentivadores e as pessoas que mais admiro, respeito e amo.

À minha esposa Daiana Lima Barreto de Santana, exemplo de mulher, companheira e amiga, que me motiva não só na construção da mais bela família ao seu lado, mas também no âmbito profissional.

Dedico. 


\section{AGRADECIMENTOS}

Aos meus amados pais, Rute Rodrigues dos Santos e José Carlos de Santana, pelos valores fundamentais, pela excelente formação acadêmica e pessoal, pelo carinho, pelos conselhos, pelo apoio incondicional, pelo exemplo de profissionalismo, de amizade, de companheirismo, de generosidade, de disciplina, de força, de fé e, principalmente, pelo amor dedicado que pretendo transmitir aos meus futuros filhos. Esta e todas as minhas conquistas serão sempre uma forma de agradecimento a vocês, que me incentivam a ser melhor a cada dia e a fazer o meu melhor sempre!

À minha esposa, Daiana Lima Barreto de Santana, pessoa ímpar, que me ensinou a sorrir, que me apoia, me incentiva, me cobra, me corrige, me fortalece, me completa. Obrigado por me fazer conhecer o sentido da palavra amor!

À Professora Doutora Ana Maria Resende Junqueira, por aceitar ser minha orientadora e me apresentar os caminhos a serem seguidos nesta jornada do Mestrado, me guiando a outros excelentes profissionais que participaram ativamente desta dissertação, além dos conhecimentos e ensinamentos agregados.

À Professora Doutora Maria Hosana Conceição, por aceitar ser minha coorientadora, sendo determinante nesta pesquisa, proporcionando também contatos multidisciplinares com professores de outras áreas, agregando conhecimentos à dissertação, sempre com humor e paciência.

Ao Professor Doutor Ernandes Rodrigues de Alencar, pelo conhecimento agregado, presteza e solicitude durante as análises com ozônio e em todos os momentos em que foi solicitado.

À Professora Doutora Eloísa Dutra Caldas por permitir que utilizássemos as instalações do Laboratório de Toxicologia da UnB para análises essenciais a esta dissertação.

À Mestre Denise Carvalho Mello, funcionária contratada do Laboratório de Toxicologia da UnB pelo auxílio em todas as análises realizadas, pelos conhecimentos e contribuições.

Aos outros professores e colegas de curso que contribuíram de alguma forma para a conclusão deste trabalho.

Aos meus familiares, amigos e colegas que sempre me apoiaram e me incentivaram. 


\section{RESUMO}

Diversas evoluções tecnológicas promoveram o desenvolvimento mundial nos mais variados setores, dentre eles no setor agropecuário. A agricultura passou por inovações de suma importância nos últimos anos, dentre elas a introdução dos agrotóxicos nas lavouras. Estes produtos podem contaminar a fauna, a flora, a água e o solo por meio da lavagem inadequada de EPIs e equipamentos usados na aplicação desses compostos. O objetivo desse trabalho foi analisar a capacidade do ozônio e da vermiculita em degradar ou adsorver o fungicida mancozebe (etilenobisditiocarbamato) em solução aquosa. Preparou-se uma solução mãe com 600mg de mancozebe comercial por litro de água (337 mg de $\mathrm{CS}_{2} / \mathrm{L}$ ) e em seguida foram feitas 5 diluições nas concentrações de 27, 54, 81, 108, e $135 \mathrm{mg}$ de $\mathrm{CS}_{2} / \mathrm{L}$. As soluções foram ozonizadas em condições previamente determinadas e o resíduo de mancozebe foi determinado na forma de $\mathrm{CS}_{2}$, pelo método espectrofotométrico. O percentual de degradação do mancozebe manteve-se com média de 99,96\%, para todas as soluções. A avaliação da adsorção do mancozebe em vermiculita foi realizada com uma solução diluída da solução mãe, com 2,40 mg de mancozebe por litro de água $\left(1,35 \mathrm{mg}\right.$ de $\left.\mathrm{CS}_{2} / \mathrm{L}\right)$ em agitação em 5,0 g de vermiculita. Esse procedimento foi realizado nos tempos de 15, 30, 45 e 60 minutos de agitação. O resíduo de mancozebe, em $150 \mathrm{~mL}$, foi determinado, na forma de $\mathrm{CS}_{2}$, pelo método espectrofotométrico. A adsorção do mancozebe pela vermiculita atingiu 99,07\% de eficiência ao final dos 60 minutos. Constatou-se ainda que, entre 15 e 30 minutos, a adsorção de mancozebe foi maior que entre 45 e 60, deduzindo-se que nos minutos iniciais os sítios ativos das lamelas da vermiculita expandida podem ter sido preenchidos mais rapidamente e, posteriormente, o percentual de adsorção foi menor, com a possibilidade de saturação dos sítios e formação de multicamadas. Outras condições de reação, pH, agrotóxicos e agentes de adsorção necessitam ser estudados.

Palavras-chave: Etilenobisditiocarbamatos, mancozebe, ozônio, oxidação, vermiculita, adsorção. 


\begin{abstract}
Several technological developments promoted global development in various sectors, including the agricultural sector. Agriculture has undergone very important innovations in recent years, among them the introduction of pesticides on crops. These products can contaminate the fauna, flora, water and soil by inadequate washing of PPE and equipment used in the application of these compounds. The objective of this study was to analyze the ozone capacity and vermiculite to degrade or adsorb mancozeb fungicide (ethylenebisdithiocarbamate) in aqueous solution. Prepared a stock solution with $600 \mathrm{mg}$ of commercial mancozeb per liter of water $\left(\mathrm{CS}_{2} 337 \mathrm{mg} / \mathrm{L}\right)$ and then 5 dilutions were made in the concentrations $27,54,81,108$, and $135 \mathrm{mg}$ of $\mathrm{CS}_{2} / \mathrm{L}$. The solutions were ozonized in predetermined conditions and mancozeb residue was determined as $\mathrm{CS}_{2}$, by the spectrophotometric method. The mancozeb degradation percentage was maintained with an average of $99.96 \%$ for all solutions. The evaluation of the adsorption of mancozeb in vermiculite was carried out with a dilute the solution with $2.40 \mathrm{mg}$ of mancozeb per liter of water $\left(\mathrm{CS}_{2} 1.35 \mathrm{mg} / \mathrm{L}\right)$ under stirring in $5.0 \mathrm{~g}$ of vermiculite. This procedure was performed in the times of 15, 30, 45 and 60 minutes of stirring. The residue mancozeb in $150 \mathrm{~mL}$ was determined as $\mathrm{CS}_{2}$, by the spectrophotometric method. The adsorption of mancozeb by vermiculite reached $99.07 \%$ efficiency at the end of 60 minutes. It was also found that between 15 and 30 minutes, mancozeb adsorption was higher than between 45 and 60, it is deducted that the initial minutes the active sites of the expanded vermiculite lamellae may have been filled faster and subsequently the adsorption percentage was lower, with the possibility of saturation of sites and formation of multilayers. Other reaction conditions, $\mathrm{pH}$, pesticides and adsorption agents need to be studied.
\end{abstract}

Keywords: Ethylenebisdithiocarbamate, mancozeb, ozone, oxidation, vermiculite, adsorption. 


\section{SUMÁRIO}

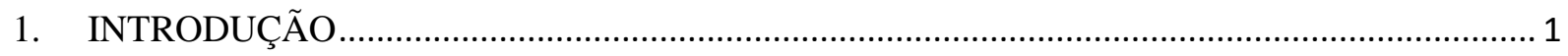

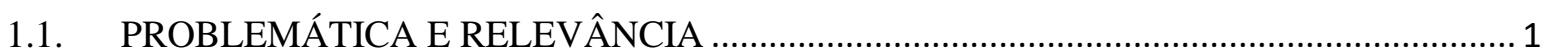

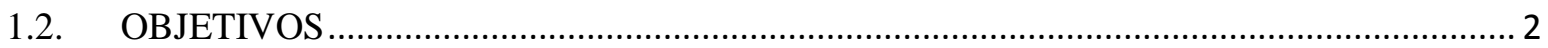

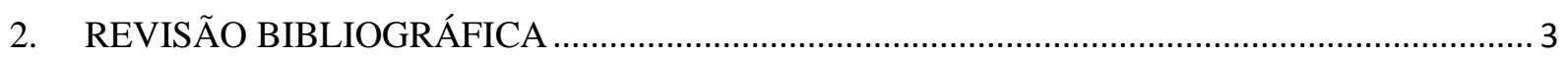

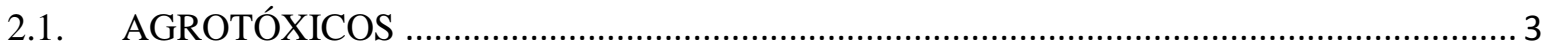

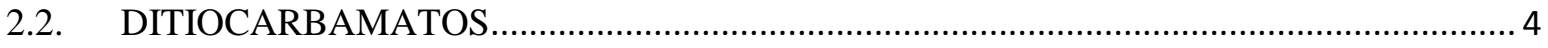

2.3. CONTAMINAÇÃO DE ÁGUA POR AGROTÓXICOS .................................................... 7

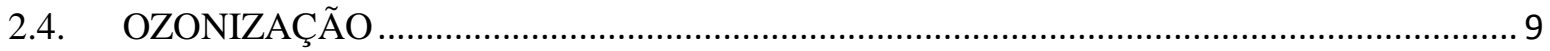

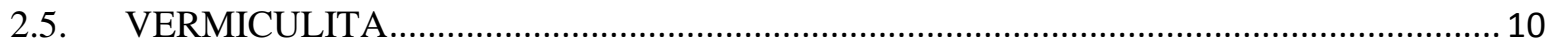

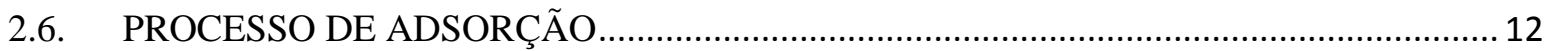

2.7. DETERMINAÇÃO DE DITIOCARBAMATOS COMO CS POR $_{2}$

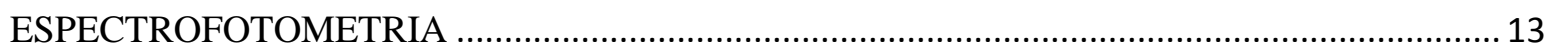

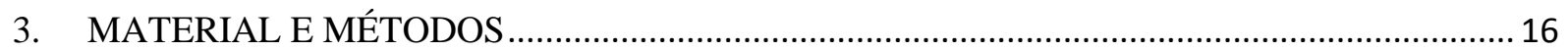

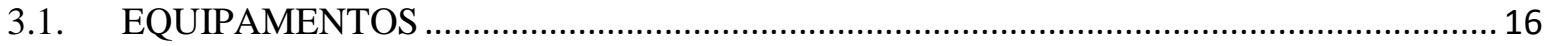

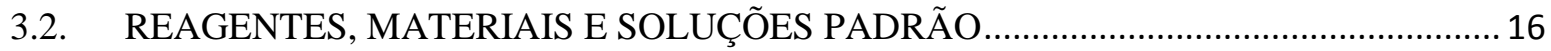

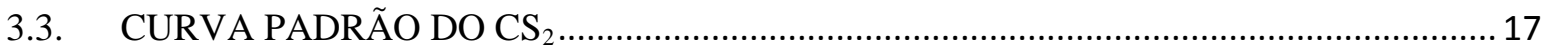

3.4. OXIDAÇÃO POR OZONIZAÇÃO DAS SOLUÇÕES DE MANCOZEBE ….................... 17

3.4.1. CONDIÇÕES INICIAIS DE PADRONIZAÇÃO DO GERADOR DE OZÔNIO E

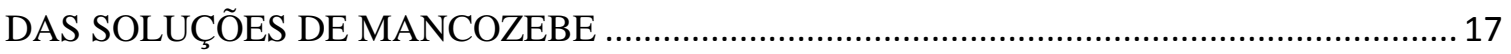

3.4.2. OZONIZAÇÃO EM CONDIÇÕES IDEAIS PRÉ-FIXADAS PARA QUANTIFICAÇÃO RESIDUAL DO MANCOZEBE ............................................................ 18

3.5. REAÇÃO DE HIDRÓLISE ÁCIDA E ANÁLISE ESPECTROFOTOMÉTRICA ............... 19

3.6. ADSORÇÃO DAS AMOSTRAS DE MANCOZEBE EM VERMICULITA ....................... 21

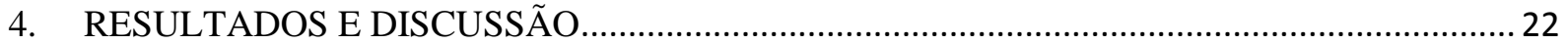

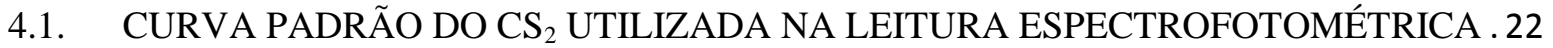

4.2. ESTUDO DA DEGRADAÇÃO POR OXIDAÇÃO COM OZÔNIO ..................................... 22

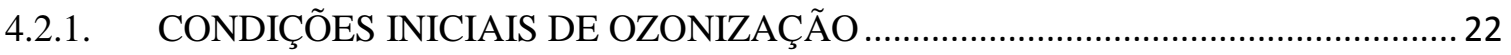

4.2.2. RESULTADOS APÓS A DETERMINAÇÃO DAS CONDIÇÕES IDEAIS DE

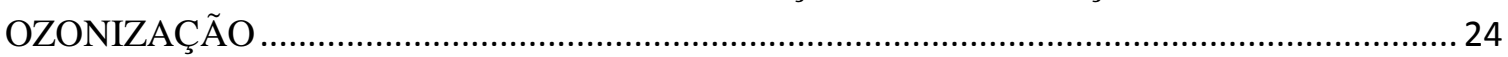

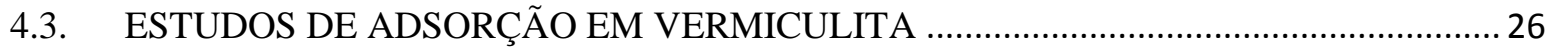

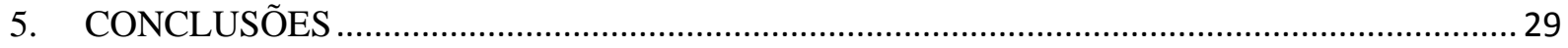

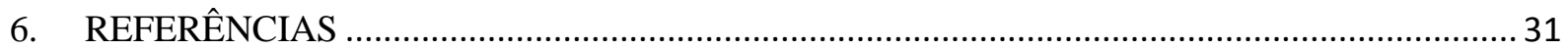




\section{LISTA DE TABELAS}

Tabela 1. Estrutura dos Ditiocarbamatos Utilizados no Brasil. 6

Tabela 2. Concentrações Iniciais/Finais e Percentual de Degradação 25

\section{LISTA DE FIGURAS}

Figura 1. Sistemas de reação vertical utilizados na determinação de ditiocarbamatos .......................... 20

Figura 2. Análise Espectrofotométrica das Amostras...................................................................... 20

Figura 3. Esquema ilustrativo do estudo de adsorção do mancozebe em vermiculita............................. 21

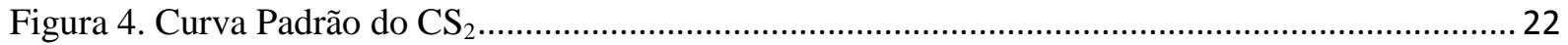

Figura 5. Soluções com 12 mg de mancozebe expostas ao ozônio ……………………...................... 24

Figura 6. Adsorção de mancozebe em vermiculita em função do tempo ..............................................27 


\section{INTRODUÇÃO}

\subsection{PROBLEMÁTICA E RELEVÂNCIA}

Grandes transformações mundiais ocorreram de forma acelerada nas últimas décadas, em sua maioria resultante dos inúmeros avanços tecnológicos. Diversos setores da economia nacional encontram-se em constante evolução devido às inovações, dentre eles a agricultura, por exemplo, impulsionada pelos avanços da indústria química com a utilização de agrotóxicos e fertilizantes, por exemplo, com vistas a garantir a sanidade agrícola e combater pragas e doenças.

A produção agrícola foi modificada, significativamente, com a inserção dessas novas tecnologias, em busca de uma produção de alimentos em larga escala. Inicialmente, foram observados apenas os aspectos positivos em relação ao uso de agrotóxicos, porém, os aspectos negativos eram até então desconhecidos, havendo poucos estudos sobre seus efeitos, tendo em vista que muitos deles ocorrem a médio/longo prazo.

Não só pela importância dos agrotóxicos no setor agrícola e sua escala de uso nacional, quanto pela influência no cenário mundial, o Governo Federal providenciou a regulamentação da produção, do registro, do uso, da aplicação, do comércio, do transporte, da armazenagem, dentre outros fatores que envolvem agrotóxicos e afins, por meio da Lei $\mathrm{n}^{\circ}$ 7802/89 e do Decreto $n^{\circ}$ 4074/02 (BRASIL, 1989).

O Brasil, segundo dados do Ministério do Meio Ambiente, é hoje o maior consumidor de agrotóxicos no mundo. Fatores como o clima favorável ao desenvolvimento de pragas agrícolas (temperatura e umidade elevadas), as grandes extensões de terras destinadas ao setor agropecuário e a escassez de mão de obra, promovem a utilização cada vez mais intensa desses produtos (BRASIL, 2015).

Devido as características de persistência muito diferenciadas e das inúmeras interações que podem surgir entre as moléculas de agrotóxicos e entre estes e os componentes do solo, da água e da atmosfera, existe hoje uma preocupação mundial com os produtos e subprodutos de agrotóxicos e suas características toxicológicas.

Assim, a tendência do uso de pesticidas não-sistêmicos de baixa toxicidade aguda, baixo custo de produção e baixa persistência ambiental fez com que fungicidas ditiocarbamatos, por exemplo, fossem largamente utilizados na agricultura (CRNOGORAC E SCHWACK, 2009). 
Segundo informações do Núcleo de Fiscalização de Insumos Agrícolas da Secretaria de Estado de Agricultura, Abastecimento e Desenvolvimento Rural do Distrito Federal (SEAGRI/DF), desde 2010, em virtude do aumento do número de fiscais neste setor (hoje novamente deficitário) e das práticas de fiscalização aliadas à educação sanitária, os produtores do Distrito Federal tiveram maior consciência sobre o perigo do uso, armazenamento e descarte incorreto de agrotóxicos e suas embalagens, mostrando uma enorme evolução do quadro, antes precário, das propriedades da região.

Um grave problema, ainda em fase de estudos, é a falta de esclarecimento em como proceder com a água utilizada nos processos de lavagem (água residual contaminada) dos utensílios utilizados na aplicação de agrotóxicos. Torna-se necessário concretizar pesquisas que apontem as formas mais adequadas de tratamento, armazenamento ou seu descarte. Por isso, observa-se que essas águas, em sua maioria, são lançadas diretamente em fossas sépticas, sumidouros, tanques de retenção improvisados, córregos ou lagos que estão às margens das propriedades, ficando o produtor sem saber as consequências negativas que essas águas contaminadas podem causar.

Assim, este trabalho se justifica devido a necessidade da descoberta de substâncias eficazes na descontaminação de águas contaminadas por agrotóxicos. Neste caso, foram selecionados o ozônio e a vermiculita como agentes de degradação e adsorção, respectivamente, do mancozebe em solução aquosa. Esse fungicida foi selecionado por seu uso em larga escala na agricultura e pela viabilidade de análise do produto pelos equipamentos laboratoriais disponíveis.

\subsection{OBJETIVOS}

\section{OBJETIVO GERAL}

O objetivo geral deste trabalho foi avaliar a eficiência do ozônio e da vermiculita como agentes de descontaminação de água com mancozebe.

\section{OBJETIVOS ESPECÍFICOS}

Determinar a degradação do mancozebe por oxidação com ozônio.

Determinar a adsorção do mancozebe em vermiculita expandida. 


\section{REVISÃO BIBLIOGRÁFICA}

\subsection{AGROTÓXICOS}

De acordo com a Lei Federal $n^{\circ} 7.802 / 89$, agrotóxicos e afins são os produtos e os componentes de processos físicos, químicos ou biológicos destinados ao uso no setor de produção, armazenamento e beneficiamento de produtos agrícolas, nas pastagens, na proteção de florestas nativas ou implantadas e de outros ecossistemas, e também em ambientes urbanos, hídricos e industriais, cuja finalidade seja alterar a composição da flora e da fauna a fim de preservá-la da ação danosa de seres vivos considerados nocivos. São ainda substâncias e produtos empregados como desfolhantes, dessecantes, estimuladores e inibidores de crescimento.

Segundo Gorza (2012), os agrotóxicos apresentam características como persistência variada e alta mobilidade, sendo em geral tóxicos no solo, na água e no ar e, em virtude de sua tendência de acumulação no solo e na biota relacionada, podem atingir as águas superficiais por escoamento, e as subterrâneas, por lixiviação. Assim, são classificados por finalidade de aplicação como:

- Inseticidas: agrotóxicos que agem no combate à insetos, larvas e formigas pertencentes a quatro grupos químicos que são os organofosforados, carbamatos, organoclorados e piretróides.

- Fungicidas: agrotóxicos que agem no combate a fungos, sendo os principais grupos químicos os etilenobisditiocarbamatos, trifenil estânico e hexaclorobenzeno.

- Herbicidas: agrotóxicos que agem no combate a ervas daninhas. Esse grupo tem apresentado utilização crescente na agricultura nos últimos anos, sendo seus principais representantes o glifosato, a atrazina e o ácido 2,4-diclorofenoxiacético (2,4-D).

Tais produtos encontram-se sob a forma de pó, grânulos, líquidos ou aerossóis, em diferentes concentrações de acordo com a utilização de controle fitossanitário, no caso, para aplicações profissionais (alta concentração) ou aplicações de uso doméstico (baixa concentração). 


\subsection{DITIOCARBAMATOS}

Em 1934, Tisdale e Wiliams sintetizaram os primeiros ditiocarbamatos a partir de uma monoamina e do dissulfeto de carbono, sendo o mais expressivo naquele momento o dissulfeto de tetrametiltiuram, também conhecido como tiram (GULLINO et al., 2010).

Posteriormente, surgiu o dimetilditiocarbamato de ferro (III), denominado ferbam, reportado por Anderson em 1940 e, independentemente, por Kincaid em 1942. O dimetilditiocarbamato de zinco, conhecido como ziram, surgiu em sequência ao ferbam, sendo mais efetivo em sua ação fungicida. Ainda em 1940, foi desenvolvido o primeiro composto etilenobisditiocarbamato (EBDC) pela empresa Rohm e Haas, Inc., o nabam, de alta solubilidade em água, mas com performance incerta devido a sua relativa instabilidade. Três anos depois, Heuberger e Manns identificaram em suas pesquisas que a adição de sulfato de zinco aprimorava a estabilidade do produto, daí o surgimento do zineb etilenobisditiocarbamato de zinco, que passou a ser comercializado como Dithane Z-78 a partir de 1945. Novos EBDCs surgiram, como o manebe (etilenobisditiocarbamato de manganês), patenteado pela DuPont (1950), produto mais eficiente que o nabam e o zineb (GULLINO et al., 2010; MELLO, 2014).

Em 1961 a Rohm e Haas desenvolveu o mancozebe, sendo este um etilenobisditiocarbamato de zinco derivado do manebe, considerado o mais importante EBDC e o fungicida mais vendido no Brasil e no mundo. Contemporâneos ao mancozebe surgiram também o metiram (alquilenobisditiocarbamato), desenvolvido pela empresa BASF, e o propinebe, reportado em 1963 (KLITTICH, 2008).

O mancozebe é indicado no controle de doenças de hortaliças e frutíferas em geral e no controle do ácaro da falsa ferrugem do citrus. Apresenta, ainda, efeito tônico em várias culturas como, por exemplo, alho e cebola, elevando substancialmente a quantidade produzida, ainda que não seja constatada a presença de pragas (SOUSA, 2009).

Segundo informações da Agência Nacional de Vigilância Sanitária, o mancozebe é um fungicida e acaricida. Seu nome químico, manganese ethylenebis dithiocarbamate, polymeric complex with zinc salt, possui a fórmula molecular $\left(\mathrm{C}_{4} \mathrm{H}_{6} \mathrm{~N}_{2} \mathrm{~S}_{4} \mathrm{Mn}\right)_{\mathrm{x}}(\mathrm{Zn})_{\mathrm{y}}$, pertence ao grupo químico dos alquilenobisditiocarbamato; sua classificação toxicológica é classe III e seu uso agrícola é indicado para aplicação foliar nas culturas de abacate, abóbora, alho, amendoim, arroz, banana, batata, berinjela, beterraba, brócolis, café, cebola, cenoura, cevada, citros, 
couve, couve flor, cravo, crisântemo, dália, ervilha, feijão, feijão-vagem, figo, fumo, gladíolo, hortênsia, maçã, mamão, manga, melancia, melão, orquídeas, pepino, pera, pêssego, pimentão, repolho, rosa, seringueira, tomate, trigo, uva e vagem.

Em síntese, os ditiocarbamatos (DCs) são compostos derivados do ácido carbâmico e encontram-se sob a forma de um pó branco ou amarelo claro, com baixa toxicidade aguda, baixa volatilidade e solubilidade em solventes orgânicos. Este grupo pode ser dividido em dimetilditiocarbamatos (DMDCs), cujos principais representantes são: ferbam, metam, tiram e ziram, e os etilenobisditiocarbamatos (EBDCs), cujos principais representantes são: manebe, mancozebe, metiram, propinebe e zineb (SOUSA, 2009; SILVA, 2005).

Os ditiocarbamatos são amplamente utilizados na agricultura brasileira no combate de fitopatologias em hortaliças, frutas e leguminosas. Eles são indicados para o uso contra doenças de folhagem, no tratamento de sementes e bulbos, contra patógenos de solo e de madeira, apresentando ainda ação repelente contra insetos (SOUSA, 2009).

Sua absorção em animais e humanos pode ocorrer pelas vias oral, dérmica e respiratória, podendo causar dermatites de contato ou apenas uma sensibilidade leve, não havendo casos sistêmicos registrados em função de sua baixa absorção. Quando ingerido em grandes doses pode ocasionar náuseas, vômitos, dores abdominais, disfunção hepática e insuficiência renal (OGA, 2003).

Ainda que todos os ditiocarbamatos liberem dissulfeto de carbono $\left(\mathrm{CS}_{2}\right)$, os EBDCs ainda podem se decompor em etilenotioureia e propilenotioureia, que são metabólitos correlacionados ao surgimento de câncer na tireoide, além da suspeita de causar mutações e terem efeitos teratogênicos (LEMES, 2003). A Tabela 1 ilustra os principais ditiocarbamatos utilizados no Brasil, em sua composição, estrutura e grupo químico. 
Tabela 1. Estrutura dos Ditiocarbamatos Utilizados no Brasil.

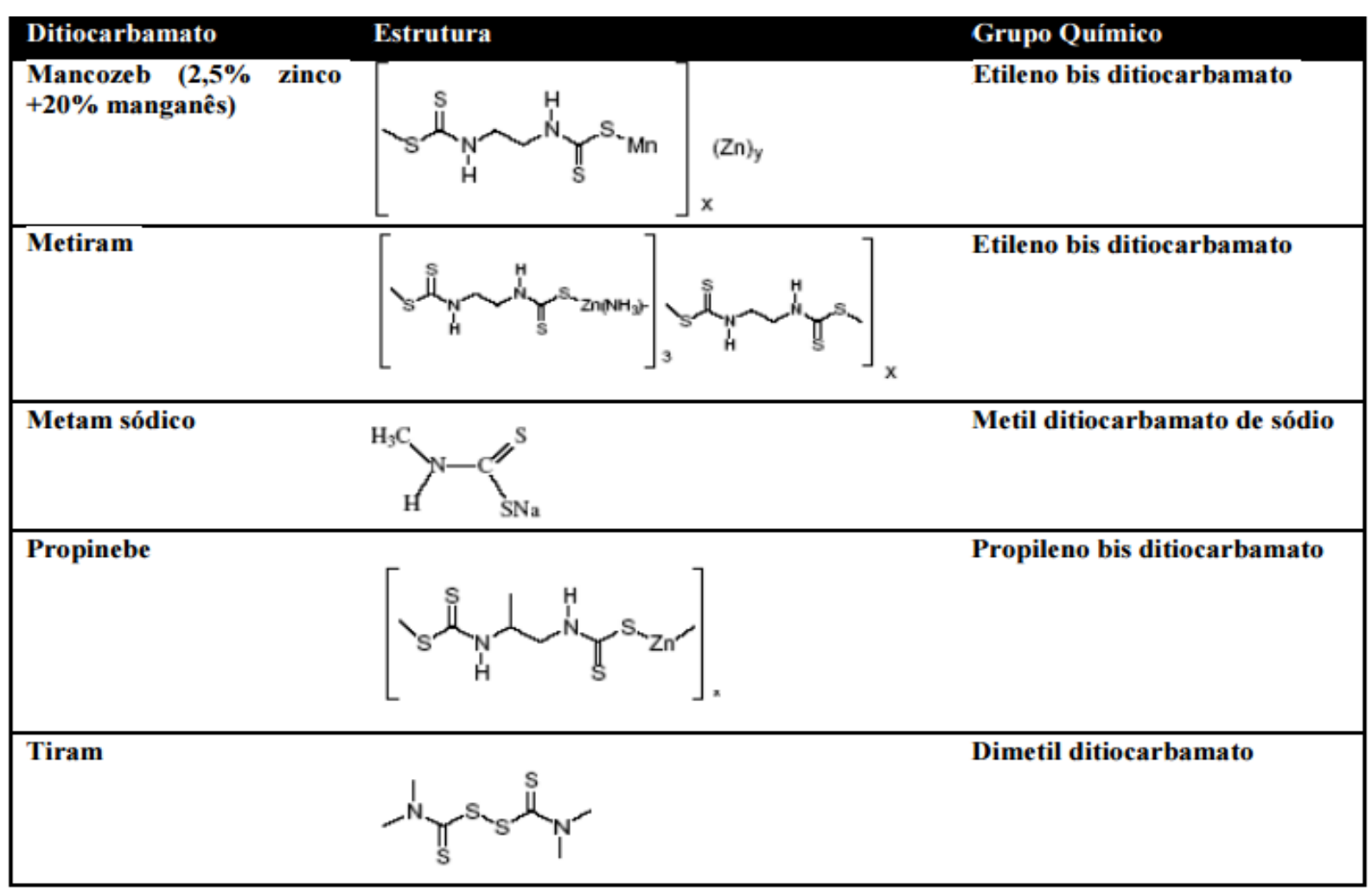

Fonte: ANVISA, 2009.

A Lei 7.802/89 estabeleceu que o Limite Máximo de Resíduo (LMR) aceito em alimentos em decorrência da aplicação adequada é expressa em partes por milhão, ppm ou $\mathrm{mg} / \mathrm{kg}$.

No Brasil, os LMRs dos princípios ativos são estabelecidos pela Agência de Vigilância Sanitária (ANVISA), durante o processo de registro do produto. Em âmbito internacional, esses limites são determinados pelo Comitê Para Resíduos de Pesticidas do Codex Alimentarius (CCPR), seguindo recomendações do JMPR (Grupo de Peritos em Resíduos de Agrotóxicos) da FAO (Organização para a Agricultura e Alimentação) / OMS (Organização Mundial de Saúde) (MELLO, 2014).

A Legislação Brasileira estabeleceu ainda que a definição de resíduos para estabelecimento de LMR para ditiocarbamatos é o $\mathrm{CS}_{2}$, comum a todos os compostos dessa classe de fungicidas, sendo expresso em $\mathrm{mg}$ de $\mathrm{CS}_{2} / \mathrm{kg}$ de amostra (CALDAS et al., 2004).

Há mais de uma década, a ANVISA, por meio de seu Programa de Análise de Resíduos de Agrotóxicos em Alimentos (PARA), vem monitorando os resíduos de ditiocarbamatos em diversos tipos de alimentos, sendo que estes têm sido encontrados, com frequência, com 
reavaliações constantes, considerando que, dos compostos autorizados, somente o tiram classifica-se em altamente tóxico, classe II, sendo os demais considerados moderadamente tóxicos, classe III.

\subsection{CONTAMINAÇÃO DE ÁGUA POR AGROTÓXICOS}

Observando os índices de resíduos em alimentos divulgados pela ANVISA e pelo Ministério da agricultura, bem como as intoxicações humanas divulgadas pelas Secretarias de Saúde, conclui-se que a necessidade de cumprimento da Lei $\mathrm{N}^{\circ} 7802 / 89$ e do Decreto $\mathrm{N}^{\mathrm{o}}$ 4074/2002 deve ser o primeiro passo para a diminuição dos casos de contaminação. A atualização dessas normativas também deve ser considerada, tendo em vista que se trata de uma legislação antiga e que dentro da realidade do tema implica em atualizações.

No Brasil, esta temática necessita de maior fomento para desenvolvimento de tecnologias mais eficazes, intensificação da pesquisa, maior acesso à informação e regulamentações mais atuais e eficientes.

A Lei Distrital no 414/93, que dispõe sobre produção, armazenamento, comercialização, transporte, consumo, uso, controle, inspeção, fiscalização e destino final de agrotóxicos, seus componentes e afins no Distrito Federal e dá outras providências, ainda não possui regulamentação e necessita de atualização. Segundo o Núcleo de Fiscalização de Insumos Agrícolas, à época, cujas atribuições estão atualmente na Gerência de Sanidade Vegetal da Secretaria de Estado de Agricultura, Abastecimento e Desenvolvimento Rural do Distrito Federal, uma nova proposta de legislação encontra-se em processo de revisão com vistas a um controle mais eficiente dessa cadeia.

Pesquisas realizadas em nossos municípios apontam que no esgoto sanitário, os resíduos de agrotóxicos e a destinação inadequada do lixo foram as causas de $72 \%$ das incidências de poluição em mananciais superficiais, $54 \%$ em poços profundos e $60 \%$ em poços rasos, segundo o Atlas de Saneamento, IBGE (2011). O uso de agrotóxicos e fertilizantes é a segunda causa de contaminação das águas no Brasil, só perdendo para o despejo de esgoto doméstico (ANVISA, 2010).

O impacto de um processo de tratamento de água na remoção de agrotóxicos e dos seus subprodutos de transformação não é de fácil mensuração, devido à grande diversidade de processos de tratamento utilizados nos sistemas de abastecimento de água e da oscilação de 
qualidade da água dos leitos. Outra limitação observada é que as técnicas necessárias à remoção de contaminantes orgânicos em água são pouco comuns à maioria das estações de tratamento de água, podendo-se constatar que tais substâncias podem estar passando inalteradas através dos processos de tratamento ou ainda transformadas em subprodutos mais perigosos que os iniciais, o que se torna um risco potencial à população (GORZA, 2012).

Os locais destinados aos tratamentos de águas, sejam elas superficiais ou subterrâneas, possuem diversas etapas e processos em sua composição, visando reduzir a quantidade de impurezas (GORZA, 2012).

Segundo Richter (1995), foi na Escócia em 1804 que se iniciou o tratamento de água para abastecimento público com o desenvolvimento do primeiro filtro lento. No Brasil, originou-se em 1880 a primeira instalação do mundo de filtração rápida, na cidade de Campos, Rio de Janeiro.

O tratamento convencional de águas superficiais define-se em um sistema multi-estágios com coagulação e floculação, sedimentação ou flotação, filtração, desinfecção e correção de pH (BOTERO, 2009). A fluoretação também é utilizada como uma etapa no tratamento convencional, pela Companhia de Saneamento Ambiental do Distrito Federal, pois contribui para redução da incidência de cárie em até $60 \%$, se as crianças ingerirem desde o nascimento quantidades adequadas de íon fluoreto (CAESB, 2016).

A Companhia de Saneamento Ambiental do Distrito Federal (Caesb), dependendo das características da água a ser tratada, adota diversos tipos de tratamento, desde um tratamento completo convencional até um tratamento mais simplificado, com cloração e fluoretação apenas.

Segundo resultados de estudos conduzidos por comissão cientifica da Agência de Proteção Ambiental dos Estados Unidos (USEPA), o tratamento convencional para fins de abastecimento público quase não possui efeito significativo sobre a remoção de agrotóxicos. Por apresentar tais limitações na sua remoção, são propostas algumas associações, tais como: adição de polímeros; utilização de processos de oxidação; utilização de materiais com capacidade de adsorção como carvão ativado, ou outros como a vermiculita; ou a associação destes (LAMBERT; GRAHAM, 1995).

Essas novas tecnologias estão sendo adotadas no Brasil para tratamentos de águas, sendo as principais a oxidação e adsorção em carvão ativado granular, mais estudadas para remoção de compostos orgânicos naturais e sintéticos (BENTAMA et al., 2004). 
O processo de oxidação química é frequentemente usado em tratamento de águas. Existem também outros sistemas de oxidação que incluem processos físicos, tais como: destruição eletroquímica e destruição fotoquímica (GORZA, 2012), e ainda processos de oxidação biológica.

\subsection{OZONIZAÇÃO}

Em 1840, o ozônio foi descoberto por Schonbein, embora tenha sido patenteado nos Estados Unidos somente em 1888 por Fewson, para eliminação de odores de esgotos. Em 1906, na França ocorre o primeiro uso de ozônio para descontaminação de água. Porém, apenas em 1940, foi instalado nos Estados Unidos o primeiro sistema comercial de tratamento de água por meio do uso de ozônio (NOVAK e YUAN, 2007; ALENCAR, 2009).

$\mathrm{O}$ oxigênio triatômico, também conhecido como gás ozônio $\left(\mathrm{O}_{3}\right)$, nada mais é do que uma reorganização molecular do oxigênio $\left(\mathrm{O}_{2}\right)$ encontrado naturalmente no meio ambiente, resultante de radiação ultravioleta, ou descargas elétricas de relâmpagos que dissociam as moléculas de oxigênio. Os radicais livres formados, altamente reativos, se reorganizam formando o $\mathrm{O}_{3}$ - ozônio (KIM et al., 1999; ALENCAR, 2009).

Por ser um gás muito reativo, mostrou-se eficiente em vários processos de desinfecção e descontaminação. Recomenda-se que sua produção artificial ocorra no próprio local de aplicação. Esse gás apresenta alta solubilidade em água em baixa temperatura e pH, apresentando uma vantagem de enorme relevância a outros agentes de descontaminação/desinfecção, pois tem como produto final o oxigênio, considerado uma tecnologia limpa, sendo um efetivo oxidante contra microrganismos (NOVAK e YUAN, 2007; ALENCAR, 2009)

O processo de uso de ozônio, chamado ozonização, tem sido muito utilizado, por exemplo, na Europa, para melhorar a qualidade da água para consumo. Além disso, essa tecnologia também tem sido adotada no tratamento de água em galões, na conservação de alimentos, no controle de pragas de grãos armazenados, na higienização de equipamentos de processamento de alimentos e desinfeção de carcaças, entre outros (HSIEH et al., 1998; MENDEZ et al., 2003; PEREIRA et al., 2008; SOUSA et al., 2008).

De acordo com o Centro Brasileiro de Bioaeronáutica - CBB (2014), o gás ozônio pode ser produzido artificialmente com a exposição do oxigênio do ar, à luz ultravioleta ou a altas 
tensões elétricas em equipamentos especiais. Desta forma, as moléculas de oxigênio do ar são desdobradas em átomos de oxigênio $\left(\mathrm{O}_{2} \rightarrow 2 \mathrm{O}\right)$ os quais se unem às outras moléculas de $\mathrm{O}_{2}$ formando o Ozônio $\left(\mathrm{O}_{3}\right)$, $\left(2 \mathrm{O}+2 \mathrm{O}_{2} \rightarrow 2 \mathrm{O}_{3}\right)$ que é um gás instável e não pode ser armazenado.

Este gás, segundo o $\mathrm{CBB}$, possui propriedades extraordinárias na desinfecção e descontaminação de vários processos relacionados com a saúde pública, sendo sua utilização condicionada principalmente ao tratamento de piscinas, de esgotos urbanos, de carnes, peixes, frutos e legumes, de resíduos hospitalares e de resíduos de agrotóxicos.

O processo de ozonização na descontaminação de agrotóxicos consiste na utilização do ozônio, que é um gás instável (de alto poder de reação) na destruição das moléculas dos agrotóxicos por oxidação. Devido a tais características, foi desenvolvido pelo CBB um aparelho denominado Descontaminador de Agrotóxicos, usado na descontaminação dos resíduos de agrotóxicos de aeronaves utilizadas na pulverização aérea.

Após pesquisas no setor, o CBB concluiu que o ozônio é o único produto que pode ser produzido nas fazendas, com tecnologia comprovada há dois séculos e com baixo preço de instalação e operação não deixando resíduos.

Com a publicação da Instrução Normativa Nº 2 de 03 de janeiro de 2008, o Ministério da Agricultura, Pecuária e Abastecimento, o Brasil se tornou pioneiro na utilização de ozônio para descontaminação de agrotóxicos no processo de lavagens de aeronaves agrícolas. Devido ao sucesso neste setor, a implantação dessa tecnologia está sendo estendida à descontaminação dos tratores, o que certamente trará benefícios incalculáveis na preservação ambiental, segundo o Centro Brasileiro de Bioaeronáutica (2014).

\subsection{VERMICULITA}

De acordo com Basset, (1963), Dana et. al., (1970), Ferraz, (1971), Kriegel, (1940), Moraes, (1944), citados por Curbelo (2002), a vermiculita tem sua origem em rochas ígneas, onde o feldspato é predominante como no granito e sienito, podendo ser encontrada também em grandes folhas nos diques de pegmatito e em muitas lavas felsíticas e pórfiras, além de alguns gnaisses e xistos, associada por diversas vezes com a muscovita, sendo menos comum nas rochas ferro-magnesianas. Em geral, são encontradas em terrenos de topografia ondulada e montanhosa. 
Segundo Curbelo (2002), a vermiculita é um silicato composto principalmente de ferro, alumínio e cálcio da família das micas, presente em grande quantidade no Brasil, com reservas no Piauí, Goiás, Paraíba e na Bahia. Esse mineral possui baixa densidade e apresenta estrutura em lamelas, sendo um material inorgânico e resistente a temperaturas elevadas. Quando submetida à alta temperatura $\left(>150^{\circ} \mathrm{C}\right)$ pode chegar a um volume até 20 vezes maior que o inicial, chamada de vermiculita expandida (MORAES, 1944; ROSEMBURG, 1969; MARTINS, 2000).

Como grande parte dos minerais, a vermiculita é hidrofílica (atrai moléculas de água e pode ser molhada), característica definida pela polaridade. Existem os minerais apolares (que não apresentam pólos negativos ou positivos) considerados hidrofóbicos e essa característica tem sido estudada e aplicada à vermiculita, obtendo-se a vermiculita hidrofobizada, que rejeita água, feita com amostras expandidas do mineral. Aplica-se em sua superfície, de forma controlada, uma camada de material orgânico (cera de carnaúba, por exemplo) chamados de coletores, fazendo com que o mineral resultante passe a atrair compostos orgânicos, processo conhecido como adsorção. Com isso, a vermiculita hidrofobizada pode retirar da água resíduos industriais como óleos, derivados de alcatrão e pesticidas (MARTINS, 2000).

Também pode ser utilizada em vazamentos de óleos por ser barato e reutilizável. Esse argilomineral é capaz de acumular quatro vezes o seu peso em petróleo, podendo ser recuperado através de solventes orgânicos (como o hexano) e reaproveitado em seguida (MARTINS, 2000).

A capacidade de troca de cátions (CTC) desse mineral é elevada, estando na faixa de 110 a 180 mEq/100g de vermiculita (Ferraz, 1971; Kriegel, 1940; Luis, 1982; Martins e Fernandes, 1992a; Martins, 1992b; Rosemburg, 1969; Santos, 1975; citados por Curbelo (2002). Suas principais características, segundo Ferraz (1971) citado por Curbelo (2002), são:

"Dureza de 1,50; Peso específico variando de 2,3 a 2,5 g/ $\mathrm{cm}^{3}$; Cor brilho, variando de castanha, amarelo-ouro ou verde, amarelo-bronze; Clivagem perfeita (001), e fraturas em lâminas flexíveis, não-elásticas; Hábitos são tabular, lamelar e escamoso; Ensaios prognósticos em via-úmida sofre decomposição pelo $\mathrm{H}_{2} \mathrm{SO}_{4}$ ".

Os principais usos e aplicações da vermiculita estão na agricultura como fertilizantes e até como pesticidas e, na horticultura, como germinador de sementes e semeador; na pecuária, sendo utilizado na alimentação animal; na construção civil também é utilizado como concreto 
isolante, isolante acústico; e, na indústria, com utilização em processos de filtração, dispersão, adsorção, além do uso como isolante térmico (altas e baixas temperaturas) (CURBELO, 2002).

\subsection{PROCESSO DE ADSORÇÃO}

O fenômeno de adsorção é definido como a capacidade de moléculas de interesse (adsorbato) contidas em um fluido (soluto) aderirem sobre a superfície de um sólido (adsorvente) (MUCCIACITO, 2006). Dentro do fenômeno da adsorção, distinguem-se duas diferentes classes de interação entre as moléculas do fluido e do sólido, baseando-se na natureza destas forças que as unem, podendo elas serem a adsorção física e a adsorção química (GORZA, 2012).

Segundo Gorza (2012), adsorção física (ou fisissorção) é o fenômeno em que as moléculas de um fluido (gás, vapor ou líquido) se concentram sobre uma superfície sólida espontaneamente, não havendo uma reação química, em que a natureza do adsorvente não é alterada, atingindo o equilíbrio de forma rápida. É considerado um processo reversível,1 dependendo das forças entre o adsorbato e o adsorvente. Ocorre devido uma diferença de energia e/ou força de atração, chamada força de Van der Waals, que tornam as moléculas fisicamente presas ao sólido. A energia envolvida nesse processo é baixa fazendo com que as moléculas do fluido possam ainda ser adsorvidas sobre as moléculas que já estão sobre o sólido, gerando as multicamadas.

$\mathrm{Na}$ adsorção química (ou quimissorção) ocorre uma transformação química da molécula com altos valores de entalpia nem sempre reversível. Segundo Valencia (2007), a quimissorção corresponde a uma interação química, onde os elétrons de enlace entre as moléculas e o sólido se reordenam em seus orbitais e mudam de forma, de modo similar a uma reação química. A entalpia na adsorção química é muito maior que a da adsorção física (RUTHVEN, 1984).

Segundo Curbelo, 2002, muitos fatores podem afetar o processo de adsorção de um composto sobre uma superfície porosa; dentre elas temos:

a) Temperatura: com a elevação da temperatura pode haver uma redução na adsorção, devido as moléculas adsorvidas terem maiores energias vibracionais, podendo, consequentemente, ocorrer sua dessorção da superfície do sólido. 
b) Natureza do solvente: este não pode competir com a superfície do sólido em atrair o soluto, tendo em vista que sua principal função é facilitar a interface e não alterá-la.

c) pH da solução: quando as substâncias a serem adsorvidas são capazes de sofrer ionização no $\mathrm{pH}$ prevalecente, o processo de adsorção pode ser prejudicado.

d) Velocidade de adsorção: a velocidade de adsorção física, por exemplo, pode estar diretamente ligada às características do fluido. Em geral, quando este é gasoso a velocidade de adsorção é maior que quando é líquido, podendo influenciar diretamente no tempo gasto para a adsorção potencial do sólido.

e) Natureza do adsorvente: deve-se observar, se a fase fluida for um gás ou um líquido, se a superfície externa ou interna do adsorvente está desenvolvida de forma a propiciar essa interação de forma a otimizar os resultados em função das suas características naturais.

f) Estrutura do poro: é importante em função do seu diâmetro, que pode agir como agente limitador no processo de adsorção permitindo que partículas de diâmetros menores possam ou não penetrar no interior do sólido, excluindo ou não aquelas com diâmetro maior.

g) Área superficial: relaciona-se muitas vezes que a quantidade que pode ser adsorvida seria diretamente proporcional a área superficial interna, o que nem sempre é verdadeiro, tendo em vista que a variabilidade no tamanho das moléculas de interesse na adsorção pode influenciar diretamente na adsorção dos sítios vazios ativos. Logo, tratamentos em superfícies de adsorventes são efetuados visando modificar drasticamente suas propriedades e carga superficial.

Dentre os adsorventes industriais mais utilizados temos o carvão ativado, a sílica-gel, a alumina ativada, a bauxita, as argilas ativadas e a vermiculita.

Não serão abordadas as isotermas de adsorção, em virtude da temática do trabalho, cujo foco não é pormenorizar os aspectos químicos da adsorção, e sim, de forma prática, determinar quantitativamente o poder de adsorção da vermiculita.

\subsection{DETERMINAÇÃO DE DITIOCARBAMATOS COMO $\mathrm{CS}_{2} \quad$ POR ESPECTROFOTOMETRIA}


Devido à característica química dos ditiocarbamatos e o fato dos EBDCs serem polímeros praticamente insolúveis em solventes orgânicos, eles tornaram-se a base para o desenvolvimento de métodos que, ainda hoje, são muito utilizados para a análise destes compostos. Estes métodos têm por base a determinação do $\mathrm{CS}_{2}$ liberado quando o ditiocarbamato, presente em um alimento ou em água, é submetido a uma hidrólise ácida. $\mathrm{O}$ $\mathrm{CS}_{2}$ formado pode ser quantificado por espectrofotometria ou por cromatografia gasosa (MELLO, 2014).

O método espectrofotométrico baseia-se na proposta de Cullen (1964), posteriormente modificada por Keppel (1969). Tal método versa sobre a determinação do complexo cúprico formado, após a liberação do $\mathrm{CS}_{2}$ durante a digestão ácida do ditiocarbamato, em cloreto de estanho como agente redutor. Este $\mathrm{CS}_{2}$ liberado é complexado em solução de acetato cúprico, dietanolamina e etanol. Esse complexo é analisado no espectrofotômetro a $435 \mathrm{~nm}$ e os resultados expressos em $\mathrm{mg} \mathrm{CS} / \mathrm{kg}$ de alimento (MELLO, 2014).

No relatório do CODEX (2003) de métodos para análises de resíduos de pesticidas o método proposto por Keppel (1971) é recomendado, apesar de o método não determinar qual o ditiocarbamato será encontrado (baixa especificidade).

Em 2001, Caldas e colaboradores modificaram a vidraria usada por Keppel (1971), propondo o novo sistema de reação vertical para análise de ditiocarbamatos, que resolveu alguns problemas apresentados no sistema tradicional horizontal. Esse sistema é relativamente robusto, compacto, de montagem e limpeza simplificada, com baixo risco de vazamentos, ocupando ainda, menos espaço de bancada. Neste sistema vertical, o balão de duas bocas, que se encontra com a amostra e o ácido, é submetido a um aquecimento. $\mathrm{O} \mathrm{CS}_{2}$ liberado é transportado no sistema vertical por um fluxo de nitrogênio, passando por uma solução de limpeza na parte inferior do sistema e complexando-se em uma solução de acetato cúprico, dietanolamina e etanol, na parte superior. Uma válvula de bloqueio consegue impedir o refluxo no sistema de $\mathrm{CS}_{2}$ produzido no balão de reação. Este $\mathrm{CS}_{2}$ complexado é analisado pelo método espectrofotométrico $(435 \mathrm{~nm})$, largamente utilizado em virtude de seu baixo custo e por possuir procedimentos práticos de poucas etapas (MELLO, 2014).

Apesar das vantagens da cromatografia, a espectrofotometria ainda continua sendo utilizada, no mundo inteiro, por ser um método de baixo custo e com resultados satisfatórios para os atuais limites estabelecidos em legislação, além de possuir procedimentos práticos de poucas etapas (CALDAS et al., 2004). 
Por outro lado, Kesari e Gupta (1998) desenvolveram um método para a determinação de tiram, ziram e zineb, utilizando a hidrólise ácida. $\mathrm{O} \mathrm{CS}_{2}$ é liberado e reage com uma solução de $\mathrm{NaOH}$ em metanol formando uma xantana que, após tratamento com iodeto de potássio e $\mathrm{N}$ - clorosuccinimida, libera iodo (I2), formando um cristal violeta pela oxidação de um leucocristal que absorve em $595 \mathrm{~nm}$, sendo este método específico para estes fungicidas.

Em 2004, Sharma et. al. propuseram um método para determinação do ziram por meio da formação de um complexo verde com molibidato de sódio, que é extraído por meio de solventes orgânicos, sendo então analisada sua espectrofotometria a $360 \mathrm{~nm}$. 


\section{MATERIAL E MÉTODOS}

\subsection{EQUIPAMENTOS}

Gerador de Ozônio modelo Ozone \& Life (O\&L) 3.0-O2 RM: Concentração de ozônio $1 \mathrm{mg} / \mathrm{L}$, vazão - 5L/min, gás de arraste - oxigênio (o equipamento possui concentrador de oxigênio). Foram utilizados frascos de vidro com tampa adaptada ao sistema e placa porosa para diminuição das bolhas de ozônio.

Espectrofotômetro modelo UV-1650 PC da marca Shimadzu, equipado com lâmpadas de tungstênio (W) e deutério (D).

Agitador magnético da marca QUIMIS, modelo Q-261-22, 220V, 552W.

\subsection{REAGENTES, MATERIAIS E SOLUÇÕES PADRÃO}

Os reagentes utilizados grau P.A., foram adquiridos da Vetec. O agrotóxico de marca comercial FORTUNA 800WP, com 80\% de mancozebe, foi adquirido da Allier Brasil Agro Ltda. por meio da revenda de agrotóxicos VEGETAL PRODUTOS AGROPECUÁRIOS. A Vermiculita expandida com granulometria superfina $(0,3 \mathrm{~mm}$ e $1,0 \mathrm{~mm})$, foi adquirida da empresa LR Paisagismo LTDA (Hobby Verde).

Soluções de trabalho, a partir do agrotóxico formulado FORTUNA, foram preparadas em um balão volumétrico de $1 \mathrm{~L}$, pesando $0,75 \mathrm{~g}$ do produto, e o volume foi completado com água comum, $\mathrm{pH}=6,7$, fornecendo uma solução de $600 \mathrm{mg} / \mathrm{L}(600 \mathrm{ppm})$ de mancozebe, equivalente a $337 \mathrm{mg}$ de $\mathrm{CS}_{2} / \mathrm{L}$, com $\mathrm{pH}=7$. A partir desta solução, foram preparadas diluições de trabalho, com água destilada de pH 5,6, com as seguintes concentrações de mancozebe: $48 \mathrm{mg} / \mathrm{L}\left(27 \mathrm{mg} \mathrm{CS}_{2} / \mathrm{L}\right), 96 \mathrm{mg} / \mathrm{L}(54 \mathrm{mg} \mathrm{CS} / \mathrm{L}), 144 \mathrm{mg} / \mathrm{L}\left(81 \mathrm{mg} \mathrm{CS}_{2} / \mathrm{L}\right), 192$ $\mathrm{mg} / \mathrm{L}\left(108 \mathrm{mg} \mathrm{CS}_{2} / \mathrm{L}\right)$, e $240 \mathrm{mg} / \mathrm{L}(135 \mathrm{mg} \mathrm{CS} / 2)$. Todas as diluições foram feitas com três repetições e $\mathrm{pH}$ médio $=6,2$, para a oxidação por ozonização. $\mathrm{Na}$ avaliação da vermiculita trabalhou-se com apenas uma diluição da solução mãe na concentração de $2,4 \mathrm{mg}$ de mancozebe/L (1,35mg $\left.\mathrm{CS}_{2} / \mathrm{L}\right)$ e $\mathrm{pH}$ médio = 6,2.

O reagente complexante usado na reação de hidrólise ácida foi preparado dissolvendo, em um balão volumétrico de $1 \mathrm{~L}, \quad 0,048 \mathrm{~g}$ de acetato cúprico monohidratado $\left(\mathrm{Cu}\left(\mathrm{CH}_{3} \mathrm{COO}\right)_{2} \cdot \mathrm{H}_{2} \mathrm{O}\right)$ e $100 \mathrm{~g}$ de dietanolamina, $\mathrm{NH}\left(\mathrm{CH}_{2} \mathrm{CH}_{2} \mathrm{OH}\right)_{2}$, e o volume completado 
com etanol. Essa solução foi armazenada a $5{ }^{\circ} \mathrm{C}$, em um frasco âmbar, até o momento do seu uso.

A solução ácida de cloreto estanoso, usada na reação de hidrólise ácida, foi preparada pela adição de $500 \mathrm{~mL}$ de ácido clorídrico concentrado, e 31,25g de cloreto estanoso dihidratado $\left(\mathrm{SnCl}_{2} \cdot 2 \mathrm{H}_{2} \mathrm{O}\right)$. A mistura foi agitada, por alguns minutos, e em seguida foi adicionada água destilada e o volume foi completado para de 2,5 L. A solução foi armazenada em temperatura ambiente em um frasco âmbar.

A solução de hidróxido de sódio, usada na reação de hidrólise ácida, foi preparada adicionando $10 \mathrm{~g}$ de $\mathrm{NaOH}$ e o volume completado para $100 \mathrm{~mL}$ com água destilada.

A solução estoque de dissulfeto de carbono foi preparada adicionando em um balão volumétrico de $50 \mathrm{~mL}$, contendo $\sim 2 \mathrm{~mL}$ de etanol e previamente pesado, 0,1 mL de dissulfeto de carbono. Em seguida, o balão foi novamente pesado para se determinar a massa exata do $\mathrm{CS}_{2}$ e o volume final foi completado com etanol. Essa solução foi utilizada para preparar as soluções diluídas de $\mathrm{CS}_{2}$, usadas na confecção da curva padrão do $\mathrm{CS}_{2}$.

\subsection{CURVA PADRÃO DO $\mathrm{CS}_{2}$}

Volumes conhecidos da solução estoque de $\operatorname{CS}_{2}(0,05 ; 0,1 ; 0,2 ; 0,5 ; 0,8 ; 1,2 ; 1,7 ; 2,0$ $\mathrm{mL}$ ) foram transferidos para 8 balões volumétricos de $25 \mathrm{~mL}$; a cada um dos balões foram adicionados $15 \mathrm{~mL}$ do agente complexante e o volume completado com etanol. Uma solução sem o dissulfeto de carbono foi preparada, nas mesmas condições, com a finalidade de determinar o ponto zero da curva. As soluções foram deixadas em repouso por $15 \mathrm{~min}$ e a absorvância foi determinada no espectrofotômetro com a lâmpada de deutério de comprimento de onda igual a $435 \mathrm{~nm}$. Com os dados de absorvância e concentração de $\mathrm{CS}_{2}$ obtidos, foi construída uma curva padrão. Para cada nova solução do reagente complexante foi preparada uma nova curva padrão.

\subsection{OXIDAÇÃO POR OZONIZAÇÃO DAS SOLUÇÕES DE MANCOZEBE}

\subsubsection{CONDIÇÕES INICIAIS DE PADRONIZAÇÃO DO GERADOR DE OZÔNIO E DAS SOLUÇÕES DE MANCOZEBE}


Inicialmente, foram testadas algumas condições, para definição de parâmetros para calibração do gerador de ozônio, com vistas a definição das melhores condições de concentração de $\mathrm{O}_{3}$ e da vazão do gás de arraste $\left(\mathrm{O}_{2}\right)$, para que os valores residuais das soluções pudessem ser quantificados dentro da curva padrão pelo método espectrofotométrico.

Trabalhou-se com as seguintes diluições a partir da solução mãe:

a) Solução com 3,6 mg de mancozebe/L de água (2 $\mathrm{mg}$ de $\left.\mathrm{CS}_{2} / \mathrm{L}\right)$, com $\mathrm{pH}=6,2$, em um tempo de 30 minutos de exposição ao ozônio, com gerador de ozônio calibrado na concentração de $9 \mathrm{mg}$ de $\mathrm{O}_{3} / \mathrm{L}$ de gás $\mathrm{O}_{2}$, em uma vazão de $2 \mathrm{~L} / \mathrm{min}$, utilizando placa porosa. Imediatamente ao término da ozonização, as triplicatas, foram levadas para a reação de hidrólise ácida e, posteriormente, seu residual foi lido no espectrofotômetro;

b) solução com $1,2 \mathrm{mg}$ de mancozebe/L de água $\left(0,7 \mathrm{mg}\right.$ de $\left.\mathrm{CS}_{2} / \mathrm{L}\right)$, com $\mathrm{pH}=6,2$ nos tempos de 1, 3 e 5 minutos de exposição ao ozônio, com gerador de ozônio calibrado na concentração de $1 \mathrm{mg}$ de $\mathrm{O}_{3} / \mathrm{L}$ de $\mathrm{O}_{2}$, em uma vazão de $5 \mathrm{~L} / \mathrm{min}$, utilizando placa porosa. Imediatamente ao término da ozonização, as triplicatas de cada tempo, foram levadas para a reação de hidrólise ácida e, posteriormente, seu residual foi lido no espectrofotômetro.

c) solução com $12 \mathrm{mg}$ de mancozebe / L de água (7 mg de $\left.\mathrm{CS}_{2} / \mathrm{L}\right)$, com $\mathrm{pH}=6,2$ nos tempos de 1, 3 e 5 minutos de exposição ao ozônio, com gerador de ozônio calibrado na concentração de $1 \mathrm{mg}$ de $\mathrm{O}_{3} / \mathrm{L}$ de $\mathrm{O}_{2}$, em uma vazão de $5 \mathrm{~L} / \mathrm{min}$, utilizando placa porosa; e no tempo de 1 minuto, nas mesmas condições anteriores, sem a utilização de placa porosa, imediatamente ao término da ozonização, as triplicatas de cada tempo, foram levadas para a reação de hidrólise ácida e, posteriormente, seu residual foi lido no espectrofotômetro.

d) solução com $384 \mathrm{mg}$ de mancozebe / L de água (215 mg de $\mathrm{CS}_{2} / \mathrm{L}$ ), com pH = 6,2 no tempo de 1 minutos de exposição ao ozônio, com gerador de ozônio calibrado na concentração de $1 \mathrm{mg}$ de $\mathrm{O}_{3} / \mathrm{L}$ de $\mathrm{O}_{2}$, em uma vazão de $5 \mathrm{~L} / \mathrm{min}$, utilizando placa porosa; imediatamente ao término da ozonização, as triplicatas de cada tempo, foram levadas para a reação de hidrólise ácida e, posteriormente, seu residual foi lido no espectrofotômetro.

\subsubsection{OZONIZAÇÃO EM CONDIÇÕES IDEAIS PRÉ-FIXADAS PARA QUANTIFICAÇÃO RESIDUAL DO MANCOZEBE}


Três amostras de $150 \mathrm{~mL}$ da solução de mancozebe na concentração $48 \mathrm{mg} / \mathrm{L}$ (27mg $\mathrm{CS}_{2} / \mathrm{L}$ ), foram expostas por um minuto ao ozônio na concentração padronizada de $-1 \mathrm{mg}$ de $\mathrm{O}_{3} / \mathrm{L}$ de $\mathrm{O}_{2}$ e vazão padronizada $-5 \mathrm{~L} / \mathrm{min}$. Esse procedimento foi repetido para as demais soluções de mancozebe trabalhadas nas concentrações $96 \mathrm{mg} / \mathrm{L}(54 \mathrm{mg} \mathrm{CS} / \mathrm{L}), 144 \mathrm{mg} / \mathrm{L}$ (81mg CS $/ \mathrm{L}), 192 \mathrm{mg} / \mathrm{L}$ (108mg CS $/ 2$ L), e $240 \mathrm{mg} / \mathrm{L}$ (135mg $\left.\mathrm{CS}_{2} / \mathrm{L}\right)$. Imediatamente ao término da ozonização, as triplicatas, foram levadas para a reação de hidrólise ácida.

\subsection{REAÇÃO DE HIDRÓLISE ÁCIDA E ANÁLISE ESPECTROFOTOMÉTRICA}

Em um balão de duas bocas, com capacidade para $500 \mathrm{~mL}$ de solução, foram colocados $150 \mathrm{~mL}$ da solução de mancozebe tratada com $\mathrm{O}_{3}$; posteriormente, foram transferidos $20 \mathrm{~mL}$ de solução de hidróxido de sódio $10 \% \mathrm{~m} / \mathrm{v}$ para a parte inferior do sistema vertical de reação e $15 \mathrm{~mL}$ de solução complexante para a parte superior do sistema. Em seguida, $175 \mathrm{~mL}$ de solução de digestão foram transferidos para o balão contendo a solução ozonizada. O balão foi colocado em uma manta aquecedora e o condensador foi conectado ao balão. Gás nitrogênio foi conectado ao balão e as partes superior e inferior do sistema foram acopladas e conectadas ao condensador. Todas as conexões foram vedadas com graxa de silicone. A válvula de nitrogênio foi aberta até a obtenção de um fluxo de gás suave e contínuo. Foi aberta também, a válvula de água para permitir sua passagem pelos condensadores. O reostato da manta aquecedora foi ajustado no máximo e, após um refluxo de vapor ter sido observado no interior do condensador, o reostato foi ajustado para uma temperatura mediana e a digestão foi conduzida por mais 45 minutos. Ao final deste tempo, o conteúdo da parte superior do sistema, contendo o $\mathrm{CS}_{2}$ na forma do complexo de cobre foi transferido, quantitativamente, para um balão volumétrico de $25 \mathrm{~mL}$ e o volume foi completado com etanol. Foi preparado um branco em um balão de $25 \mathrm{~mL}$, contendo $15 \mathrm{~mL}$ de solução complexante e o volume foi completado com etanol. A Figura 1, ilustra o sistema vertical usado nas reações de hidrólise ácida. Por fim, as amostras foram lidas no espectrofotômetro, Figura 2, no comprimento de onda de $435 \mathrm{~nm}$ e quantificadas com a curva padrão previamente preparada; o resultado foi dado em $\mathrm{mg}$ de $\mathrm{CS}_{2} / 25 \mathrm{~mL}$ de solução. 


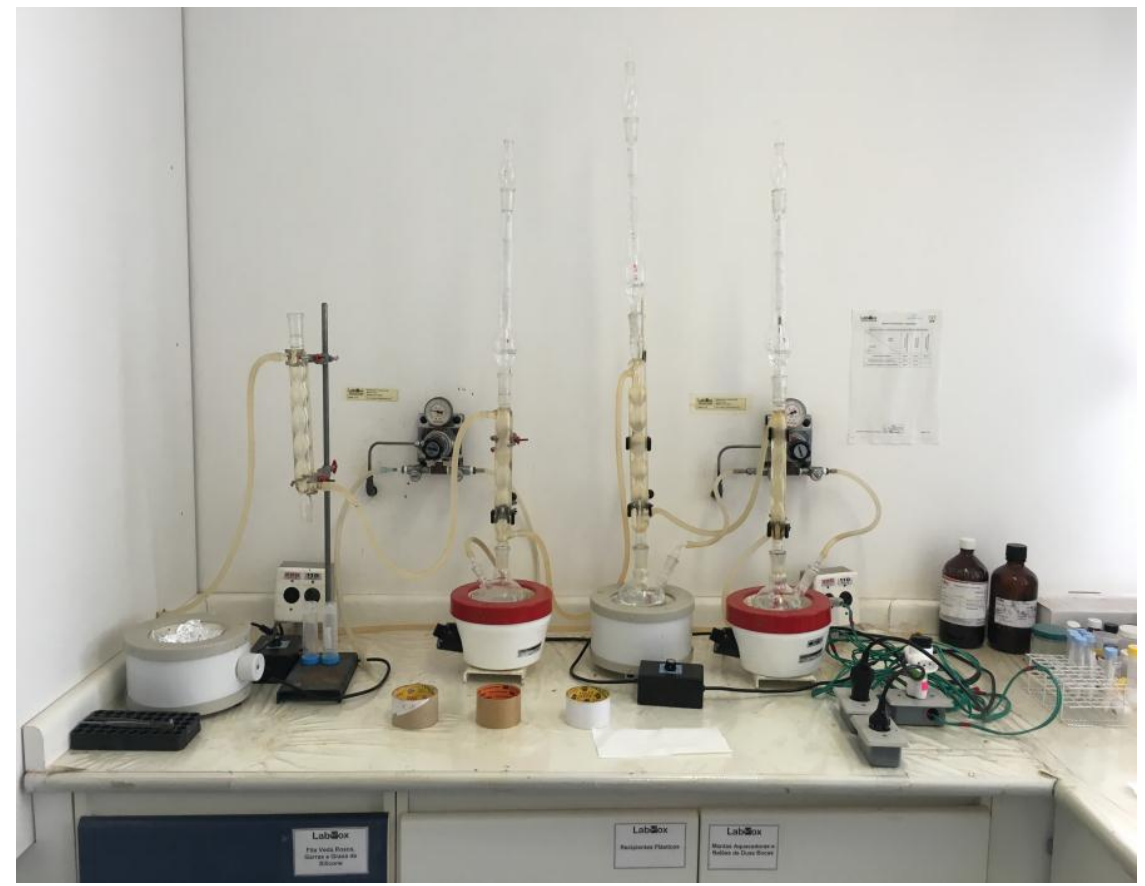

Figura 1. Sistemas de reação vertical utilizados na determinação de ditiocarbamatos

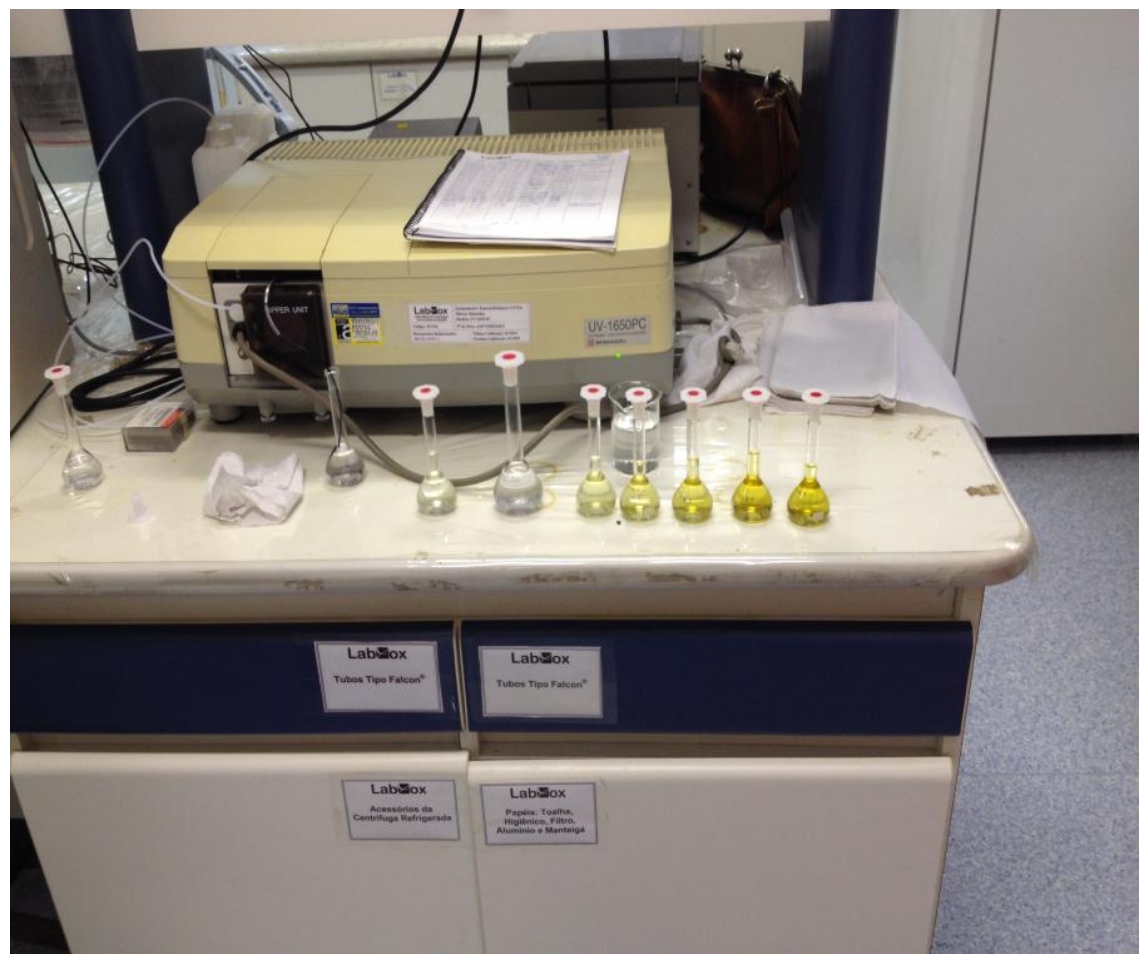

Figura 2. Análise Espectrofotométrica das Amostras 


\subsection{ADSORÇÃO DAS AMOSTRAS DE MANCOZEBE EM VERMICULITA}

Para avaliar a adsorção do fungicida mancozebe na vermiculita, foram tomados $500 \mathrm{~mL}$ da solução de concentração 2,4 mg de mancozebe / L de água (1,35 mg CS $2 / \mathrm{L})$ preparada a partir da solução de $600 \mathrm{mg}$ de mancozebe/L de água. Essa solução foi agitada com $5 \mathrm{~g}$ de vermiculita por um período de 15 minutos. O experimento foi repetido para os tempos de contato de 30, 45 e 60 minutos. Após cada tempo, a mistura resultante foi filtrada em papel de filtro (filtração rápida) e o filtrado foi dividido em triplicata de $150 \mathrm{~mL}$ e levados para o sistema de digestão ácida, conforme descrito no item 3.5. e ilustrado na Figura 3. Em seguida, as soluções resultantes foram lidas no espectrofotômetro e a quantidade de mancozebe, na forma de $\mathrm{CS}_{2}$, foi determinada.

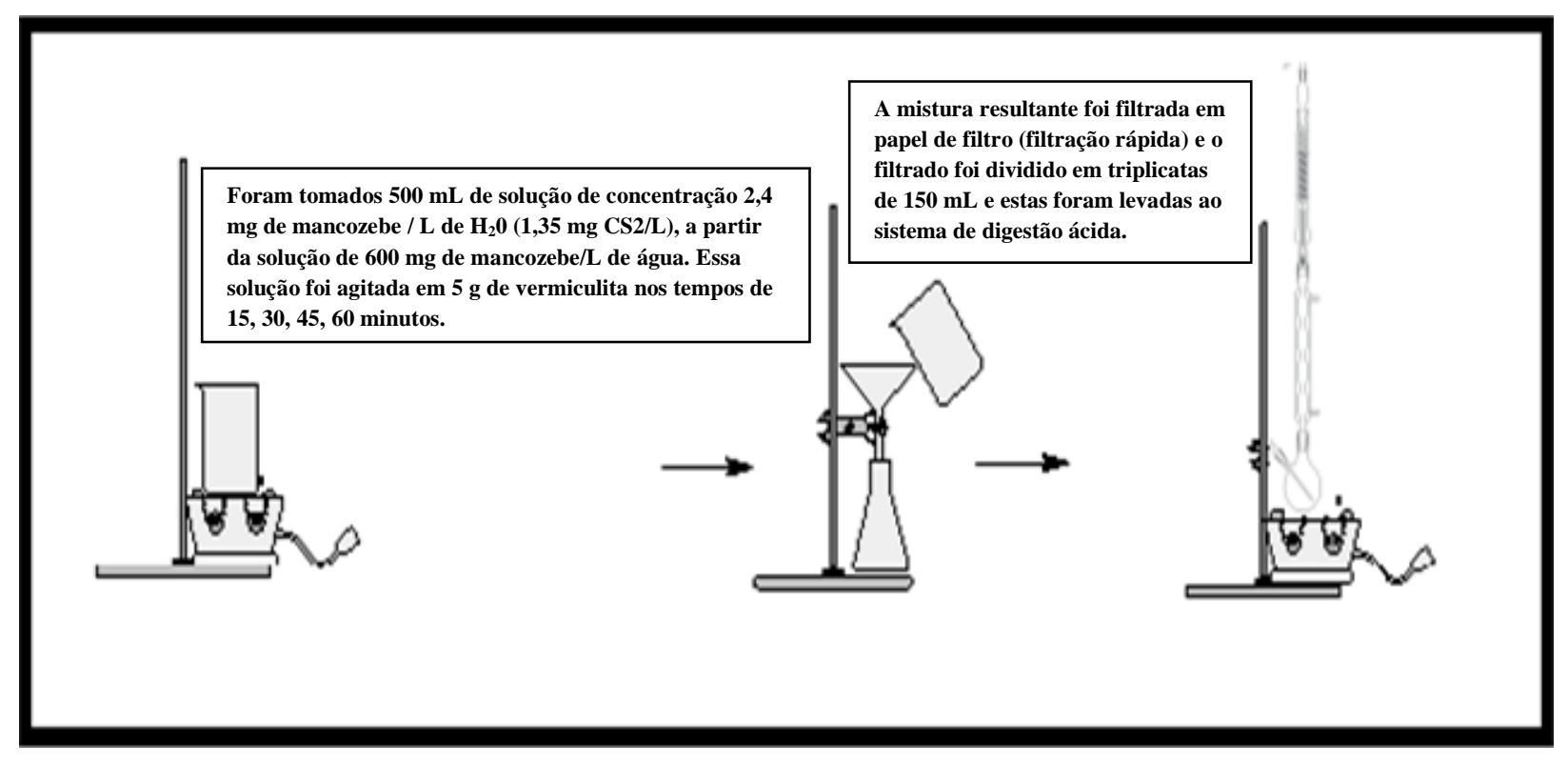

Figura 3. Esquema ilustrativo do estudo de adsorção do mancozebe em vermiculita 


\section{RESULTADOS E DISCUSSÃO}

\subsection{CURVA PADRÃO DO $\mathrm{CS}_{2}$ UTILIZADA NA LEITURA ESPECTROFOTOMÉTRICA}

A curva padrão de $\mathrm{CS}_{2}$, ilustrada na Figura 4, foi obtida com os dados das leituras da absorvância de soluções diluídas com volumes conhecidos de $\mathrm{CS}_{2}$. Este padrão é utilizado nos estudos desenvolvidos no Laboratório de Toxicologia da UnB.

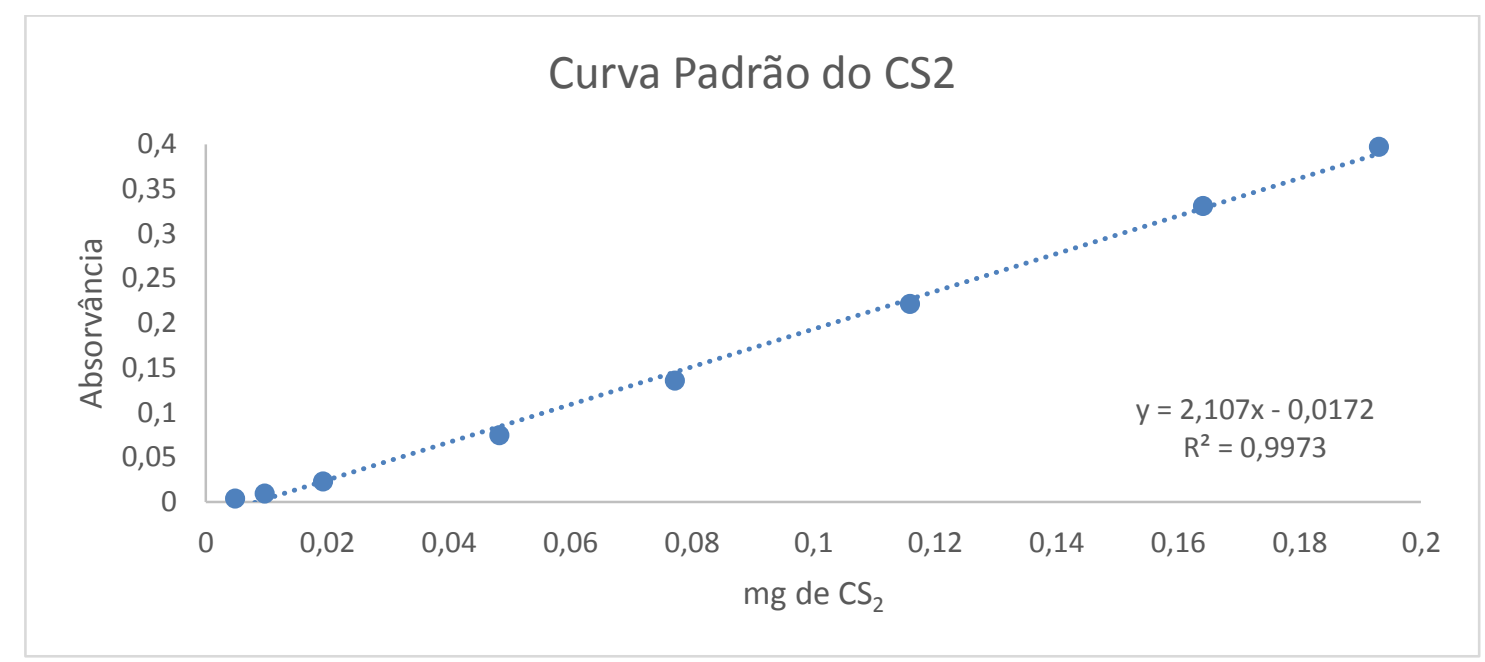

Figura 4. Curva Padrão do $\mathrm{CS}_{2}$

Conforme está ilustrado na Figura 4, o valor de $\mathrm{R}^{2}$ de 0,9973 indica uma linearidade dos pontos da curva padrão, tendo em vista que, quanto menor a dispersão dos pontos experimentais, menor a incerteza dos coeficientes de regressão estimados, assegurando uma qualidade da curva obtida.

\subsection{ESTUDO DA DEGRADAÇÃO POR OXIDAÇÃO COM OZÔNIO}

\subsubsection{CONDIÇÕES INICIAIS DE OZONIZAÇÃO}

As condições iniciais de ozonização descritas no item 3.4.1., não permitiram a quantificação do $\mathrm{CS}_{2}$ na faixa de linearidade da curva padrão. 
Considerando a solução com 3,6 mg de mancozebe/L de água (2 mg de $\left.\mathrm{CS}_{2} / \mathrm{L}\right), \mathrm{pH}=$ 6,2, com gerador de ozônio calibrado na concentração de $9 \mathrm{mg}$ de $\mathrm{O}_{3} / \mathrm{L}$ de gás $\mathrm{O}_{2}$ e vazão de 2L/min, com tempo de 30 minutos de exposição ao ozônio com a utilização de placa porosa, o valor residual de $\mathrm{CS}_{2}$ não foi considerado pois foi abaixo do LOQ (limite de quantificação ) do método, cuja quantificação não é precisa, indicando concentração menor que $0,0048 \mathrm{mg}$ de $\mathrm{CS}_{2}$, concluindo-se uma degradação em torno de 100|\%, com valor residual tendente a zero.

Da mesma forma, não consideramos a solução com $1,2 \mathrm{mg}$ de mancozebe/L de água $(0,7$ $\mathrm{mg}$ de $\mathrm{CS}_{2} / \mathrm{L}$ ), $\mathrm{pH}=6,2$, com gerador de ozônio calibrado na concentração de $1 \mathrm{mg}$ de $\mathrm{O}_{3} / \mathrm{L}$ de $\mathrm{O}_{2}$ e vazão de 5L/min, nos tempos de 1, 3 e 5 minutos de exposição ao ozônio com a utilização de placa porosa, pois o seu valor residual também estourou a curva em seu ponto mínimo, sugerindo degradação em torno de $100 \%$.

No caso da solução com $12 \mathrm{mg}$ de mancozebe / L de água $\left(7 \mathrm{mg}\right.$ de $\left.\mathrm{CS}_{2} / \mathrm{L}\right)$, com $\mathrm{pH}=$ 6,2, com gerador de ozônio calibrado na concentração de $1 \mathrm{mg} \mathrm{de} \mathrm{O}_{3} / \mathrm{L}$ de $\mathrm{O}_{2}$ e vazão de 5L/min, apenas no tempo de 1 minuto de exposição ao ozônio (com e sem placa porosa), a concentração residual chegou a cair na curva, porém praticamente no seu ponto mínimo, sendo por isso descartada. Sendo assim, foi utilizada como balizador para definição das concentrações mínimas ideais ao experimento.

Ressalta-se que o uso de placa porosa, determina apenas, a formação de bolhas menores do gás, com vistas a otimizar a ação do ozônio nas soluções, ainda que para efeitos práticos o uso ou não de placa porosa, não tenha alterado significativamente as reações deste experimento e por isso não foi analisado em separado. Padronizamos, no entanto, as análises sempre com a utilização de placa porosa. A Figura 5 exemplifica o procedimento de ozonização para a solução de $12 \mathrm{mg}$ de mancozebe nos tempos de 1,3 e 5 minutos com a utilização de placa porosa. 


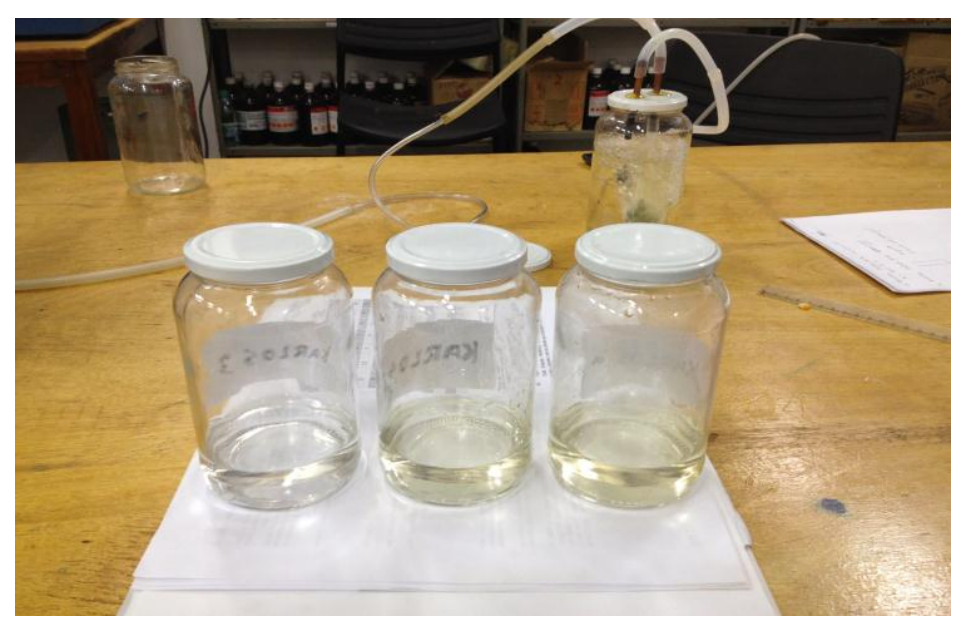

Figura 5. Soluções com $12 \mathrm{mg}$ de mancozebe expostas ao ozônio pelos tempos de 1, 3, 5 minutos.

A solução com $384 \mathrm{mg}$ de mancozebe / L de água (215 mg de $\mathrm{CS}_{2} / \mathrm{L}$ ), com pH =6,2, com gerador de ozônio calibrado na concentração de $1 \mathrm{mg}$ de $\mathrm{O}_{3} / \mathrm{L}$ de $\mathrm{O}_{2}$ e vazão de $5 \mathrm{~L} / \mathrm{min}$, no tempo de 1 minuto de exposição ao ozônio utilizando placa porosa, apresentou concentração residual que estourou a curva em seu ponto máximo, cuja quantificação também não é precisa. Ainda sim, também contribuiu como balizador para a definição o ponto máximo ideal a ser trabalhado no experimento.

\subsubsection{RESULTADOS APÓS A DETERMINAÇÃO DAS CONDIÇÕES IDEAIS DE OZONIZAÇÃO}

A reação de oxidação com ozônio das soluções aquosas de mancozebe nas concentrações de $48 \mathrm{mg} / \mathrm{L}(27 \mathrm{mg} \mathrm{CS} / \mathrm{L}), 96 \mathrm{mg} / \mathrm{L}$ (54mg CS $2 / \mathrm{L}), 144 \mathrm{mg} / \mathrm{L}(81 \mathrm{mg} \mathrm{CS} / \mathrm{L}), 192 \mathrm{mg} / \mathrm{L}$ $\left(108 \mathrm{mg} \mathrm{CS} \mathrm{CS}_{2} / \mathrm{L}\right)$ e $240 \mathrm{mg} / \mathrm{L}(135 \mathrm{mg} \mathrm{CS} / \mathrm{L})$ forneceu um percentual médio de degradação do mancozebe de $99,75 \%$.

A tabela a seguir, detalha o percentual de degradação do mancozebe com o uso de ozônio, em relação às concentrações iniciais de mancozebe (também expressa em $\mathrm{CS}_{2}$ ) nas soluções e as concentrações finais deste composto após o processo de ozonização. 
Tabela 2. Concentrações Iniciais/Finais e Percentual de Degradação

\begin{tabular}{cccc}
\hline $\begin{array}{c}\text { Concentração inicial de } \\
\text { mancozebe }(\mathrm{mg} / \mathrm{L})^{*}\end{array}$ & $\begin{array}{c}\text { Concentração } \\
\text { inicial de dissulfeto } \\
\text { de carbono } \\
\left(\mathrm{mg} \mathrm{CS}_{2} / \mathrm{L}\right)^{* *}\end{array}$ & $\begin{array}{c}\text { Concentração final } \\
\text { de dissulfeto de } \\
\text { carbono } \\
\left(\mathrm{mg} \mathrm{CS}_{2} / \mathrm{L}\right)\end{array}$ & \% de Degradação \\
\hline 48 & 27 & 0,0120 & 99,96 \\
96 & 54 & 0,0128 & 99,98 \\
144 & 81 & 0,0290 & 99,96 \\
192 & 108 & 0,0472 & 99,96 \\
240 & 135 & 0,0507 & 99,96 \\
\hline
\end{tabular}

* Para preparar as soluções diluídas utilizou-se a expressão $c_{1 .} \mathrm{v}_{1}=\mathrm{c}_{2} \mathrm{v}_{2}$ Ex: $600 \mathrm{mg} / \mathrm{L} .40 \mathrm{~mL}=\mathrm{c}_{2} .48 \mathrm{mg} / \mathrm{L} \rightarrow \mathrm{c}_{2}$

$=48 \mathrm{mg} / \mathrm{L}$. Os cálculos foram realizados da mesma forma para as demais diluições.

** Para transformar a unidade de concentração de mancozebe/L para $\mathrm{CS}_{2} / \mathrm{L}$, utilizou-se como base o cálculo abaixo:

$271,2 \mathrm{mg}$ de mancozebe $\rightarrow 152,28 \mathrm{mg}$ de $\mathrm{CS}_{2}$

$48 \mathrm{mg}$ de mancozebe $\rightarrow \mathrm{X} \quad \ldots \quad \mathrm{X}=27 \mathrm{mg}$ de $\mathrm{CS}_{2}$

Um resultado semelhante ocorreu na utilização de ozônio para o tratamento de resíduos de compostos citostáticos, que são medicamentos usados nos hospitais para o tratamento de pacientes com câncer, recentemente estudado. Os pesquisadores coletaram água do esgoto de um hospital da Espanha e trataram com ozônio. Os resultados demonstraram uma total remoção para os quatro fármacos estudados (FERRE-ARACIL, 2016). Comprova-se que o uso do ozônio apresenta altíssima eficiência, com os mais variados compostos, sendo estudado como agente de descontaminação em diversos setores.

Os resultados da degradação estão em conformidade, também,com aqueles observados por Garcia et al. (2013), em que foi avaliada a degradação do herbicida amicarbazona em solução aquosa com o uso da oxidação por ozônio sob irradiação Ultravioleta-UV (considerada uma oxidação avançada). Em seu estudo, chegou-se a um percentual superior a $99 \%$ de degradação do composto em até 20 minutos de reação.

Alguns fatores podem ter influenciado nesses resultados, como por exemplo a variação de pH das amostras. Observou-se no trabalho de Garcia et al. (2013), que o efeito do aumento de $\mathrm{pH}$ influenciou negativamente na remoção do carbono orgânico total, sugerindo que a degradação do pesticida tenha sido retardada com esse aumento, devido à decomposição do 
ozônio nessas condições e a formação insuficiente de radicais hidroxila, concluindo-se que em $\mathrm{pH}=4$, a ação molecular via direta, do ozônio, mostrou-se mais favorável.

Ainda nos estudos de Garcia et al. (2013), um fator relevante observado foi a concentração de amicarbazona. Em baixas concentrações do pesticida a velocidade de degradação foi de quase $100 \%$ em menos de 40 minutos para quase todas as condições de seu experimento. Já em altas concentrações de ozônio, para este trabalho, observou-se a degradação total da amicarbazona em tempos inferiores a 20 minutos, inferindo-se que o aumento da concentração desse gás influencia diretamente no aumento da velocidade de degradação do pesticida.

No tocante a variação de $\mathrm{pH}$, nos estudos de Usharani, (2012), a eficácia do processo foi estimada com base no grau de DQO (Demanda Química de Oxigénio) com a decomposição do organofosfato (metilparathion) em função do aumento de radicais hidroxilas formados durante a ozonização. Observou-se que a ozonização, neste caso, foi mais eficaz na reação alcalina frente às outras condições. O grau de conversão de metilparathion obtido após 120 minutos do processo, em $\mathrm{pH}=9$, foi de $98 \%$ em comparação com $81 \%$ e $60 \%$ em $\mathrm{pH}=7$ e $\mathrm{pH}=3$, respectivamente. Observa-se então que, dependendo do composto e da estrutura molecular, pode-se ter um resultado diverso em condições de $\mathrm{pH}$ semelhantes. Estimula-se portanto o estudo mais aprofundado da ação de conversão, quebra ou degradação do ozônio frente as características estruturais químicas dos compostos a ele submetidos.

Outros fatores podem ainda contribuir para favorecer ou não essa degradação, como: vazão do gás, o tamanho da molécula a ser degradada e a concentração do composto, influenciando diretamente no tempo de degradação por ozônio.

\subsection{ESTUDOS DE ADSORÇÃO EM VERMICULITA}

Observou-se que, com o aumento do tempo de exposição das soluções à vermiculita, mantendo-se a concentração de mancozebe das amostras constante, o percentual de adsorção também aumentou, apesar deste aumento não ter se dado de forma constante. Ao se analisar esses valores, concluiu-se que, entre os tempos de 15 e 30 minutos, o percentual de adsorção ocorreu mais rapidamente que entre 45 e $60 \mathrm{~min}$.

A Figura 6 representa a evolução de adsorção de mancozebe ao longo do tempo de exposição à vermiculita. 


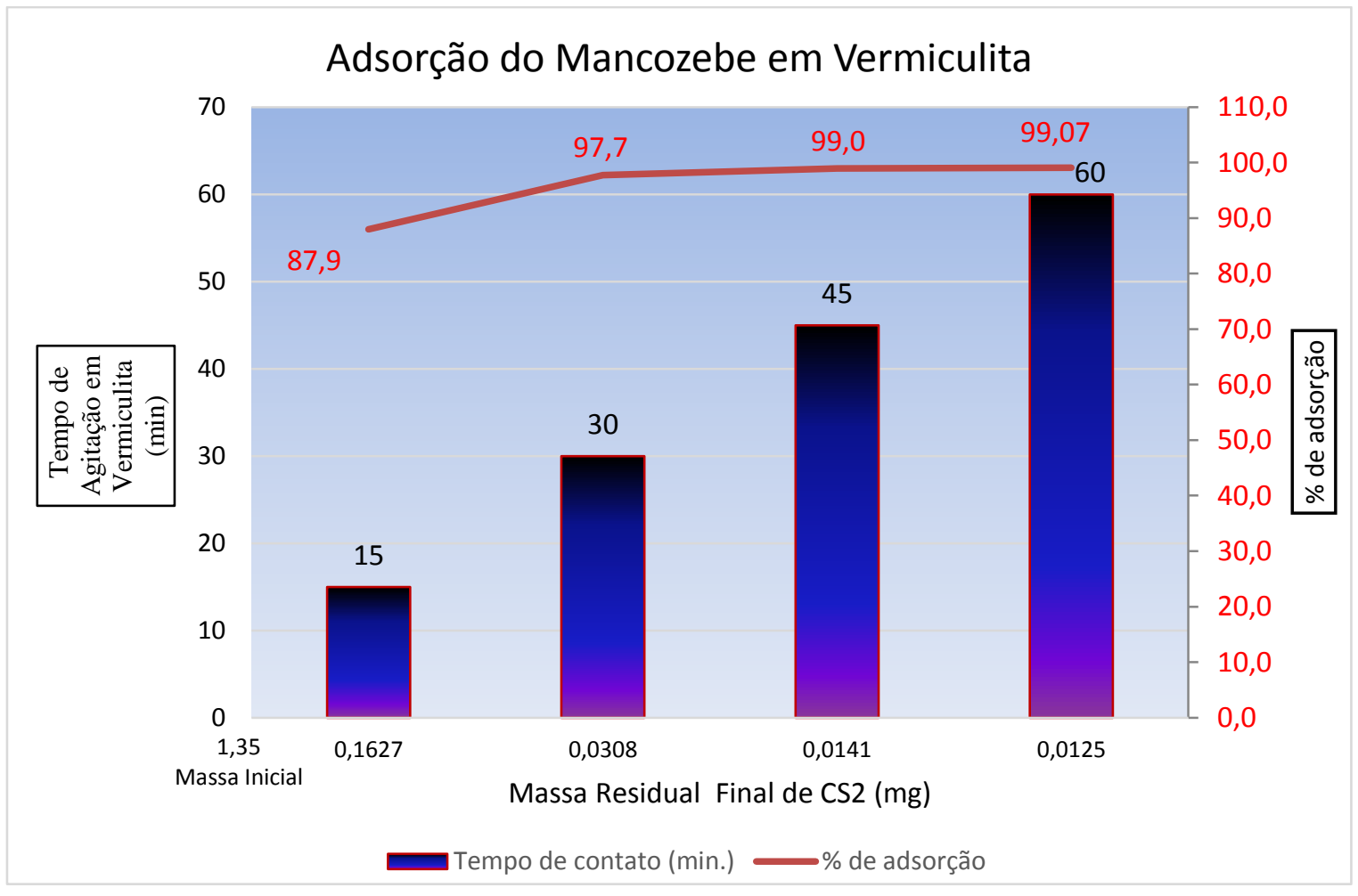

Figura 6. Adsorção de mancozebe em vermiculita em função do tempo

Sendo assim, frente aos estudos desenvolvidos nesta dissertação, infere-se que a capacidade de adsorção da vermiculita expandida para as soluções trabalhadas, tem sua capacidade ótima nos 30 primeiros minutos. Posteriormente a este tempo, os sítios ativos das lamelas podem estar sendo preenchidos e a sua capacidade de adsorção tende a diminuir. Ainda assim, ao final de $60 \mathrm{~min}$. praticamente todos os $1,35 \mathrm{mg}$ de $\mathrm{CS}_{2} / \mathrm{L}$ foram adsorvidos nas $5 \mathrm{~g}$ de vermiculita, fornecendo uma eficiência de $99,1 \%$ de adsorção do mancozebe.

Nos estudos do artigo publicado por Guimarães et. al. (2014), avaliou-se a remoção do glicerol livre presente no biodiesel por sorção em vermiculita. Observou-se nesta pesquisa que a vermiculita alcançou excelentes índices de adsorção, com os valores residuais em massa de glicerol livre, menores que o estipulado pela ANP; porém, comparado com uma resina comercial usada para este mesmo fim, a vermiculita reduziu os teores mais rapidamente, em cerca de 30 minutos, enquanto que a resina comercial levou cerca de 60 minutos para alcançar o mesmo valor. 
Análogo ao trabalho supracitado, no experimento desta dissertação a vermiculita também teve um percentual mais alto de adsorção nos primeiros 30 minutos, o que nos leva a inferir que o material pode apresentar um potencial ótimo de adsorção nesse intervalo de tempo, e a medida que suas lamelas e sítios ativos vão sendo preenchidos seu percentual tende a decair.

Outro aspecto relevante a ser considerado é a capacidade da vermiculita em adsorver compostos orgânicos diversos, como pesticidas, o que a torna um material de amplo espectro de utilização para os mais variados materiais, além de possuir um baixo custo. 


\section{CONCLUSÕES}

O ozônio e a vermiculita, dentro das condições adotadas nesta dissertação, apresentaram um alto percentual de degradação pelo $\mathrm{O}_{3}$ ou adsorção pela vermiculita frente ao mancozebe, mostrando-se eficientes em relação aos objetivos propostos.

O ozônio degradou quase $100 \%$ do mancozebe em água, de todas as soluções trabalhadas nas condições estabelecidas neste experimento. Logo, estimula-se a continuidade dos estudos deste gás para outras condições e variáveis. O uso desta tecnologia com outros princípios ativos devem ser fomentados, no intuito de aperfeiçoar as melhores condições para sua utilização, detectando-se as melhores formas de se potencializar sua eficiência. Explorar alternativas como a detecção de um pH ideal para um determinado composto, o estabelecimento de uma concentração de gás ideal para maximização do rendimento, os tipos de moléculas que podem ser mais facilmente degradadas pelo ozônio em função de sua composição e características químicas, são sugestões à continuidade deste experimento.

Outros aspectos de grande relevância, como os aspectos econômicos da utilização do ozônio, devem ser explorados. O custo de implementação, com vistas à descontaminação de águas residuais da agricultura, por exemplo, ao se instalar um gerador de ozônio no campo, necessita de maiores estudos, em função, por exemplo, do tamanho da propriedade rural a ser instalado um gerador, ou mesmo a escala de uso, frente ao volume de água com resíduos de agrotóxicos produzida no local, e até mesmo os tipos de agrotóxicos utilizados.

Os estudos com a vermiculita e sua capacidade de adsorção de mancozebe em água também se mostrou muito eficiente chegando a percentuais maiores que $99 \%$ de adsorção ao final de 60 minutos. Isso demonstra que este componente de baixo custo e de grande abundância, pode se tonar uma solução ambientalmente sustentável para descontaminação de águas com resíduos de agrotóxicos, porém, também necessita mais estudos e aperfeiçoamento em sua utilização.

Vale salientar que a vermiculita apenas adsorve o produto, necessitando a continuidade dos estudos no aprimoramento da retirada dos agrotóxicos adsorvidos por este material e se estes, poderiam ser reaproveitados, ou, caso não seja possível, sugere-se ainda estudos para definição da destinação mais adequada ou do melhor tratamento a ser dado ao novo resíduo gerado, vermiculita + agrotóxico. 
A utilização da vermiculita em grandes, médias e pequenas propriedades rurais, por exemplo, é outro ponto a ser discutido, em virtude do custo e eficiência deste material para cada realidade agrícola.

Já o uso do ozônio e da vermiculita simultaneamente ou alternadamente, também necessita de maiores pesquisas e discussões, para adequação de um sistema eficiente e viável.

Logo, infere-se que não necessariamente um agente de descontaminação é melhor que o outro, mas que a condição de utilização de cada um deles pode ser determinante na sua escolha, porém, pode-se sim deduzir que, dentro do objetivo inicial desta dissertação, tanto o ozônio como a vermiculita, apresentaram uma alta capacidade de degradação e adsorção, respectivamente, em relação ao princípio ativo mancozebe. 


\section{REFERÊNCIAS}

ALENCAR, E. R. Processo de ozonização de amendoim (Arachis hypogaea L.): cinética de decomposição, efeito fungicida e detoxificante de aflatoxinas e aspectos qualitativos. 2009. 107 p. Tese (Doutorado) - Programa de Pós-Graduação em Engenharia Agrícola. Universidade Federal de Viçosa, Minas Gerais, Viçosa, 2009.

ANVISA - Agência Nacional de Vigilância Sanitária. Programa de Análise de Resíduos de Agrotóxicos em Alimentos. Brasília, DF, 2009.

ANVISA - Agência Nacional de Vigilância Sanitária. Relatório de atividades 2010. Brasília, DF, 2010.

BENTAMA, J.; SCHMITZ, P.; DESTRAC, P.; ESPENAN, J.M. Technological innovation for the production of drinking water by membrane processes. Desalination 168, p. 283-286, 2004.

BOTERO, W. G. Caracterização de lodo gerado em estações de tratamento de água: perspectivas de aplicação agrícola. Quim. Nova, v. 32, No. 8, p. 2018-2022, 2009.

BRASIL. Decreto no 4.074, de 04/01/2002. Regulamenta a Lei $n^{\circ} 7802$ de 11 de julho de 1989. Diário Oficial da União, República Federativa do Brasil, Brasília, 08/01/2002. Disponível em: <http://www.planalto.gov.br/ccivil_03/decreto/2002/D4074.htm.> Acesso em 10 de dezembro de 2014.

BRASIL. Instrução Normativa $N^{\circ}$ 2, de 3 de janeiro de 2008. Aprova as normas de trabalho da aviação agrícola. Diário Oficial da União, República Federativa do Brasil, Brasília 08/01/2008. Disponível em: <http://www.agricultura.gov.br/arq_editor/file/Agrot\%C3\%B3xicos/IN2.pdf> Acesso em: 05 de fevereiro de 2015. 
BRASIL. Lei $\mathrm{n}^{\circ}$ 7802, de 11 de julho de 1989. Dispõe sobre a pesquisa, a experimentação, a produção, a embalagem, e rotulagem, o transporte, o armazenamento, a comercialização, a propaganda comercial, a utilização, a importação, a exportação, o destino final das embalagens vazias, o registro, a classificação, o controle, a inspeção e a fiscalização de agrotóxicos, seus componentes e afins, e dá outras providências. Diário Oficial da União, República Federativa do Brasil, Brasília, 12/07/1989. Disponível em: <http://www.planalto.gov.br/ccivil_03/Leis/L7802.htm>. Acesso em: 09 de dezembro de 2014.

BRASIL. Ministério do Meio Ambiente, Segurança química, Agrotóxicos, 2015. Disponível em <http://www.mma.gov.br/seguranca-quimica/agrotoxicos> Acesso em: 22 de novembro de 2015.

CAESB - Companhia de Saneamento Ambiental do Distrito Federal, Fluoretação da àgua, Disponível em: <https://www.caesb.df.gov.br/agua/unidades-de-tratamento8.html> Acesso em: 02 de fevereiro de 2016.

CALDAS, E. D., CONCEIÇÃO, M. H., MIRANDA, M. C. C.,SOUZA, L. C. K. R., LIMA, J. F. Determination of dithiocarbamate fungicide residues in food by a spectrophotometric method using a vertical disulfide reaction system. J. Agric. Food Chem., v. 49, n. 10, p. 45214525, 2001.

CAldAS, E. D., MIRANDA, M. C. C., CONCEIÇÃO, M. H., SOUZA, L. C. K. R. Dithiocarbamates residues in brazilian food and the potential risk for consumers. Food and Chem. Toxic., v. 42, p. 1877-1883, 2004.

CENTRO BRASILEIRO $\mathrm{DE}$ BIOAERONÁUTICA $(\mathrm{CBB})$ (http://www.bioaeronautica.com.br/equipamentos/descontaminador-de-agrotoxicos.php). Acesso em 21 de dezembro de 2014. Brasília, 2014.

CODEX - Codex Alimentarius Comission. Guidelines on good laboratory practice in residue analysis. FAO/WHO: Rome. CAC/GL 40-1993, Rev.1-2003. 
CRNOGORAC, G.; SCHWACK, W. Residue analysis of dithiocarbamate fungicides. Trends in Analytical Chemistry, v. 28, n. 1, p. 40-50, 2009.

CULLEN, T. E. Spectrophotometric determination of dithiocarbamates residues on food crops. Analytical Chemistry v.36, p. 221-224, 1964.

CURBELO, F. D. S. Estudo da remoção de óleo em águas produzidas na indústria de petróleo, por adsorção em coluna utilizando a vermiculita expandida e hidrofobizada. Dissertação de mestrado, Universidade Federal do Rio Grande do Norte, Natal, RN, Brasil, 2002. Disponível em: http://www.nupeg.ufrn.br/documentos_finais/dissertacoes_de_mestrado/dissertacoes/fabiola.p df> Acesso em: 07 de abril de 2015.

DISTRITO FEDERAL. Lei $n^{\circ} 414$ de 15 de janeiro de 1993. Dispõe sobre produção, armazenamento, comercialização, transporte, consumo, uso, controle, inspeção, fiscalização e destino final de agrotóxicos, seus componentes e afins no Distrito Federal e dá outras providências. Diário Oficial do Distrito Federal, Brasília, DF, ano XVII, nº 12 , seção única, 1996, p. 5-6.

FERRE-ARACIL，J.; VALCÁRCEL, Y.; NEGREIRA, N.; LÓPEZ DE ALDA, M.; BARCELÓ, D.; CARDONA, S.C.; NAVARRO-LABOULAIS, J. Ozonation of hospital raw wastewaters for cytostatic compounds removal. Kinetic modelling and economic assessment of the process Science of The Total Environment, Volume 556, 2016, p. 70-79.

GARCIA, J. P. V. Estudo da degradação do pesticida amicarbazona em meio aquoso por processo de oxidação avançada baseado em ozônio. Dissertação de mestrado, 151 p. Universidade de São Paulo, São Paulo, 2013.

GUIMARÃES. R., COSTA, A. E., GOUVÊA, C. A. K., ANDREAZZA, J. K. Remoção do glicerol livre presente no biodiesel por sorção em vermiculita. XX Congresso Brasileiro de Engenharia Química, 2014. 8 p. 
GORZA, N. L. Remoção de Agrotóxicos em uma Instalação Piloto de Tratamento de Águas de Abastecimento do Tipo Convencional, Associado à Pré-Oxidação e Adsorção em Carvão Ativado Granular. Dissertação de mestrado, Universidade Federal do Espírito Santo, Vitória, ES, $\quad 2012$ Brasil, Disponível em: $<$ http://www.ct.ufes.br/ppgea/files/disserta\%C3\%A7\%C3\%A3o\%20Nadja\%20Lima\%20Gorz a.pdf> Acesso em: 15 de novembro de 2014.

GUlliNO, M.L.; TINIVELlA, F.; GARIBALDI, A.; KEMMITT, G.M.; BACCI, L.B. Mancozeb past present and future, Plant Disease, 2010.

HSIEH, S.P.Y.; NINQ, S.S.; TZENG, D.D.S. Control of turf grass seedborne pathogenic fungi by ozone. Plant Pathology Bulletin, v.7, p.105-112, 1998.

IBGE (Instituto Brasileiro de Geografia e Estatística). Atlas de Saneamento 2011. Disponível em:

<http://www.ibge.gov.br/home/estatistica/populacao/atlas_saneamento/default_zip.shtm> Acesso em: 01 de fevereiro de 2016.

KEPPEL, G. Modification of the carbon disulfide evolution method for dithiocarbamate residues. J. Assoc. Off. Anal.Chem., v. 52, p.162-167, 1969.

KEPPEL, G.E. Collaborative study of the determination of dithiocarbamate. Residues by a modified carbon disulfide evolution method. Journal of AOAC 54, 528-532, 1971.

KESARI, R., GUPTA V. K Sensitive spectrophotometric method for the determination of dithiocarbamate fungicide and its application in environmental samples Talanta Volume 45 (6), p. 1097-1102, 1998.

KIM, J.G.; YOUSEF, A.E.; DAVE, S. Application of ozone for enhancing the microbiological safety and quality of foods: a review. Journal of Food Protection. v.62, n.9, p.1071-1087, 1999. 
KLITTICH, C.J. Milestones in fungicide discovery: Chemistry that changed agriculture. 2008. Online. Plant Health Progress. Disponível em <http://www.plantmanagementnetwork.org/pub/php/review/2008/milestones>. Acessado em: 03/02/2016.

LAMBERT, S. D; GRAHAM, N. J. D. A comparative evaluation of the effectiveness of potable water filtration processes. Water SRT-Aqua, vol. 44, n.1, p.38-51, 1995.

LEMES, V. R. R. Avaliação de Resíduos de Ditiocarbamatos e Etilenotiouréia (ETU) em Fruta e sua Implicação na Saúde Pública e Ambiental. Dissertação de Mestrado em Saúde Pública São Paulo. Universidade de São Paulo, São Paulo, 129 p 2003.

MARTINS, J.; Vermiculita é transformada em mineral hidrofóbico, por Mara Figueira, Ciência Hoje, Jornal do Brasil, Rio de Janeiro - RJ, 2000.

MELLO, D. C. determinação dos fungicidas ditiocarbamatos, etilenobisditiocarbamatos (ebdc) e propinebe em alimentos por HPLC-UV. 2014. 119p. Dissertação (Mestrado em Ciências da Saúde) - Programa de Pós Graduação em Ciências Farmacêuticas. Universidade de Brasília, Distrito Federal, Brasília, 2014.

MENDEZ, F.; MAIER, D. E.; MASON, L. J.; WOLOSHUK, C. P. Penetration of ozone into columns of stored grains and effects on chemical composition and performance. Journal of Stored Products Research, v.39, n.1, p.33-44, 2003.

MORAES, L. J. Vermiculita no Brasil, Bol. 45, FFCLUSP (Geologia), pág. 29-33, São Paulo - SP, 1944.

MUCCIACITO, J. C. Conceitos e aplicações do carvão ativado. Revista e Portal Meio Filtrante, São Paulo, Ano V - Edição $n^{\circ} 22$ - set./out. 2006. Disponível em: < http://www.meiofiltrante.com.br/materias.asp?id=254> Acesso em: 18 de dezembro de 2014. 
NOVAK, J.S.; YUAN, J.T.C. The ozonation concept: advantages of ozone treatment and commercial developments. In: Tewari, G.; Juneja, V.K. (Eds.) Advances in Thermal and NonThermal Food Preservation. Ames: Blackwell Publishing, 2007, p.185-193.

PEREIRA, A.M. ; FARONI, L.R.D.; SOUSA, A.H.; URRUCHI, W.I.; PAES, J.L. Influência da temperatura da massa de grãos sobre a toxicidade do ozônio a Tribolium castaneum. Revista Brasileira de Engenharia Agrícola e Ambiental, v.12, p.493-497, 2008.

RICHTER, Carlos A.; AZEVEDO NETTO, José M. de. Tratamento de água. 1.reimpressão. São Paulo: Edgard Blücher, 332 p, 1995.

ROSEMBURG, J. P. Vermiculitas brasileiras e usos industriais, Cerâmica, vol. 15 (59), pág. 195, 1969.

RUTHVEN, D. M, Principles of adsorption and adsorption processes. John Wiley: Sons, New York, 1984.

OGA, S. Fundamentos de toxicologia. $2^{\mathrm{a}}$. ed. São Paulo: Atheneu, 2003. 474 p.

SHARMA, V. K. S. AULAKH J.S. MALIK A.K. Fourth derivative spectrophotometric determination of fungicide (tetramethyldithiocarbamate) using sodium molybdate and its application. Food Chemistry. v. 47, p 1524-1529, 2004.

SILVA, R. C. Comparação entre métodos cromatográficos, empregando GCECD, GC-FPD, e GC-MS e espectrofotométrico para determinação de ditiocarbamatos em alface. Dissertação de mestrado em química analítica). Universidade Federal de Santa Maria, 2005.

SOUSA, A.H. ; FARONI, L.R.D.; GUEDES, R.N.C.; TÓTOLA, M.R. ; URRUCHI, W.I. Ozone as a management alternative against phosphine-resistant insectpests of stored products. Journal of Stored Products Research, v.44, p.379-385, 2008. 
SOUSA, L. A. F. Validação de metodologia analítica para determinação de resíduos de fungicidas ditilcarbamato em tomate por espectrofotometria. Dissertação de mestrado. Belo Horizonte, Universidade Federal de Minas Gerais (UFMG), 89 p., 2009.

USHARANI, K.; MUTHUKUMAR, M.; KADIRVELU, K. Effect of pH on the degradation of aqueous organophosphate (methylparathion) in wastewater by ozonation, International Journal of Environmental Research, 6(2): 557 - 564 (2012).

VALENCIA, C. A. V. Aplicação da adsorção em carvão ativado e outros materiais carbonosos no tratamento de águas contaminadas por pesticidas de uso agrícola. Dissertação de Mestrado. Pontifícia Universidade Católica do Rio de Janeiro, Rio de Janeiro, RJ, 116 p., 2007. 